\title{
Análise simplificada de custos de Tecnologia
}

de Informação

\section{Herbert Kimura}

Doutorado em Administração de Empresas pela

Fundação Getulio Vargas (FGV)

Professor titular da Universidade de Brasília (UnB)

herbert.kimura@gmail.com

\section{Luiz Carlos Jacob Perera}

Doutorado em Administração pela Universidade de São Paulo (USP)

Pós-Doutorado pela Université Pierre Mendès France

Professor Adjunto III, no Programa de Pós-Graduação

em Ciências Contábeis da Universidade Presbiteriana

Mackenzie

jperera@mackenzie.br

\section{Maria Thereza Pompa Antunes}

Doutorado em Controladoria e Contabilidade pela

Universidade de São Paulo (USP)

Professora e pesquisadora da Universidade

Presbiteriana Mackenzie

mariathereza@mackenzie.com.br
ISSNe 2178-9258

ISSN 1678-2089

Organização: Comitê Científico Interinstitucional

Editor Científico: José Carlos Lázaro

Avaliação: Double Blind Review pelo SEER/OJS

Revisão: Gramatical, normativa e de formatação Recebido em 16-11-2009

Aprovação Final em 19-12-2012

\section{RESUMO:}

A Tecnologia de Informação (TI) foi uma das áreas mais dinâmicas do século 20 e, na entrada deste novo milênio, percebe-se a tecnologia fortemente integrada a quase todos os aspectos do cotidiano. Enormes volumes de recursos têm sido direcionados às áreas de TI, chegando a representar, em média, cerca de $40 \%$ dos investimentos de capital de uma empresa. Neste trabalho, é discutido um mecanismo de gerenciamento de custos de áreas de TI. Na abordagem proposta, o preço dos serviços prestados pelo departamento de TI envolve uma margem de lucro adicionada ao custo que é apurado segundo atividades. Uma vez que não existem modelos consagrados de gestão de custos de TI, neste trabalho procura-se trazer ao debate um modelo simplificado que agrega um mecanismo de controladoria utilizando conceitos de custeio baseado em atividades com as diretrizes de gestão de tecnologia fundamentadas no CobiT (Control Objectives for Information and Related Technology). Para ilustrar o modelo proposto, foi realizado um estudo de caso sobre análise de custos de TI de uma instituição de ensino superior de São Paulo.

Palavras-chave: Tecnologia de informação. Custeio baseado em atividade. Gestão de custos. Centro de resultados. Objetivos de controle.

\section{ABSTRACT:}

Information Technology (IT) was one of the most dynamic areas of the 20th century and, in the beginning of this new millennium, technology is strongly integrated in almost all aspects of our daily life. Large volumes of resources have been directed to IT areas, totaling, on average, about $40 \%$ of capital expenditures of a company. In this study, we discuss a mechanism for IT cost management. In the proposed approach, the price of the services rendered by the IT department involves a markup added to the cost, which is assessed based on activities. Once definite models of IT cost management do not exist yet, in this study, we bring to the debate a simplified approach that integrates a mechanism of financial control using costing concepts based on activities with the guidelines of technology management based on CobiT (Control Objectives for Information and Related Technology). To illustrate the proposed model, we conducted a case study of IT cost analysis of a higher education institution in Sao Paulo.

Keywords: Information technology. Activity-based costing. Cost management. Profit center. Control objectives. 


\section{INTRODUÇÃO}

A Tecnologia de Informação (TI) foi uma das áreas mais dinâmicas do século 20 e, na entrada deste novo milênio, percebe-se a tecnologia fortemente integrada a quase todos os aspectos do cotidiano. Enormes volumes de recursos têm sido direcionados às áreas de TI, chegando a representar em média cerca de $40 \%$ dos investimentos de capital de uma empresa (CARR, 2007).

Apesar da relevância de TI tanto em termos estratégicos associados a vantagens competitivas quanto em termos de volumes de investimento, o estabelecimento de custos de TI é um assunto extremamente complexo que não é muito bem tratado e contemplado por praticantes, consultores ou acadêmicos (BANNISTER, MCCABE e REMENYI, 2001). Estudo realizado com 335 CEOs e CIOs em 21 países sugere que um dos grandes problemas nas empresas é a visão inadequada do desempenho de TI (ITGI, 2004).

De acordo com Neumann et al. (2004), a gestão de custos está cada vez mais ligada à Tecnologia de Informação. De fato, com a revolução dos ativos de TI ocorrida nas duas últimas décadas, as organizações apresentam uma preocupação crescente com o custo total de propriedade desses ativos (OPFER, 2001). Em uma ampla pesquisa realizada com executivos sêniores de TI provenientes de 472 organizações, Luftman e Zadeth (2011) identificam que produtividade e redução de custos do negócio representam preocupação primordial. Em particular, a redução de custos de TI constitui uma meta frequente das empresas (LUFTMAN e BEM-ZVI, 2010; LUFTMAN e ZADETH, 2011). Adicionalmente, uma vez que a competitividade pode depender de investimentos em tecnologia, serviços prestados por centros de informação estão sendo fortemente demandados nas organizações (DRURY, 1998). Assim, a gestão e o controle de custos tornam-se atividades importantes para o desempenho da empresa.

Cronholm e Goldkuhl (2003) lembram que uma avaliação nunca representa uma tarefa fácil e, consequentemente, existem diversas sugestões para analisar um sistema de TI. Oh e Pinsonneault (2007), inclusive, argumentam que, apesar de mais de 20 anos de intensas pesquisas, não existe um consenso sobre o valor estratégico da tecnologia de informação. Considerando que custos de tecnologia podem atingir patamares elevados, O'Leary (1992) cita que áreas de tecnologia de informação sofrem forte pressão devido aos fatores: (i) orçamentos decrescentes; (ii) maior exigência da alta administração; (iii) maior variedade de clientes e competidores, inclusive de alternativas de terceirização. Em especial, a terceirização de atividades de TI tem impacto prático relevante, conforme destacam Lacity, Khan e Willcocks (2009). Nesse contexto, os departamentos de TI estão descobrindo que devem demonstrar seu valor (DRURY, 1998), fato que explica o desenvolvimento de métricas que suportem a área de TI como um núcleo que não somente induz custos como também gera receitas (CROWLEY, 1994). Sob a perspectiva de avaliação de desempenho do uso de recursos de TI, torna-se, portanto, importante o estabelecimento de um modelo de gestão que proporcione a identificação de direcionadores de custos e a atribuição de preço de transferência para áreas usuárias.

Neste trabalho, é discutido um mecanismo de gerenciamento de custos de áreas de TI. O objetivo do artigo é, portanto, apresentar uma proposta de modelo de avaliação de custos de TI, considerando os diversos mecanismos de precificação e eventuais análises a partir de custeio baseado em atividades. O modelo proposto é acompanhado de um estudo de caso de uma área de TI de uma organização. No modelo, evidencia-se o estabelecimento da área de TI como centro de responsabilidade que, de acordo com Anthony e Govindarajan (2002), representa uma unidade da organização sob supervisão de um executivo responsável pelas atividades dela. Privilegia-se uma abordagem de centro de resultado, no qual o preço dos serviços prestados pelo departamento de TI envolve uma margem de lucro adicionada ao custo que, por sua vez, é apurado segundo um mecanismo baseado em atividades.

Portanto, a perspectiva tratada neste trabalho apresenta três características: (i) departamento de TI como cento de resultado; (ii) preço do serviço prestado equivalente ao custo adicionado a uma margem de lucro; (iii) custeio 
dos serviços baseado em atividades. De certa maneira, as duas primeiras características têm uma forte ligação, uma vez que a avaliação de desempenho de um centro de resultado deve estar atrelada a variáveis de custo e de receita. A terceira característica reflete a complexidade dos serviços e produtos gerados pelos departamentos de TI que, em geral, não são adequadamente avaliados segundo critérios de gestão de custos baseados em função, nos quais mecanismos de rateio são comumente utilizados.

Visando desenvolver uma metodologia de avaliação mais adequada às especificidades de serviços das áreas de TI, o método de gestão de custos analisado neste trabalho considera um custeio baseado em atividades ou custeio $\mathrm{ABC}$ (activity-based costing), que permite levantar, de maneira mais acurada, o nível de recursos gastos ou investidos com a prestação dos serviços de TI.

Apesar de o uso do ABC para avaliação de custos de serviços em empresas de TI já ter sido discutido, por exemplo, por Neumann et al. (2004) em uma empresa americana e por Corrêa (2002) em uma pequena empresa brasileira de informática, neste trabalho busca-se construir uma estrutura de análise genérica de atribuição de preços usando um modelo de custos baseado em atividades usando padrões internacionais de gestão de tecnologia como diretrizes. Mais especificamente, dentro das orientações do CobiT (Control Objectives for Information and related Technology), publicado pelo ITGI (Information Technology Governance Institute), propõe-se uma estrutura de avaliação de custos de serviços de TI. Deve-se esclarecer a priori que não há a ambição de que o modelo contemple todas as peculiaridades de situações ou serviços e de que o modelo proposto seja superior a outros métodos para avaliação da área de TI. Além disso, em função de benefícios e custos ocultos, mecanismos tradicionais de avaliação de TI são comumente incompletos (RYAN e HARRISON, 2000).

Assim, reiterando, uma vez que não existem modelos consagrados de gestão de custos de TI, procura-se trazer ao debate, neste trabalho, um modelo simplificado, que agrega mecanismos de controladoria financeira utilizando conceitos de custeio baseado em atividades com as diretrizes de gestão de tecnologia fundamentadas no CobiT. Dessa forma, são integrados dois mecanismos consagrados de gestão, o CobiT e o Activity Based Cost $(\mathrm{ABC})$, a um instrumento de efetivo de gerenciamento e controle. Este artigo encontra-se, a seguir, dividido em quatro partes: (i) na primeira parte, são apresentados conceitos sobre estrutura de TI e direcionadores de custos, com ênfase em custeio baseado em atividades; (ii) na segunda parte, são discutidos modelos de precificação de atividades da área de TI; (iii) na terceira parte, propõe-se um modelo teórico de avaliação de custos de TI e procede-se a um estudo de caso da área de TI de uma instituição de ensino superior; (iv) na quarta parte, expõem-se os comentários finais sobre o estudo.

\section{ESTRUTURA E DIRECIONADORES DE CUSTO (ABC)}

\subsection{Estrutura de análise de custos de TI}

A relevância da gestão de custos de TI é evidenciada pelo tratamento específico abordado no documento CobiT preparado pelo ITGI. O CobiT 4.1 (2007) sugere, em um item específico do domínio de Produção e Suporte (DS6), uma estrutura de controle sobre o processo de identificação e alocação de custos de TI, conforme ilustra a Figura 1.

\section{Figura 1 - Descrição do processo de identificação e alocação de custos de TI}

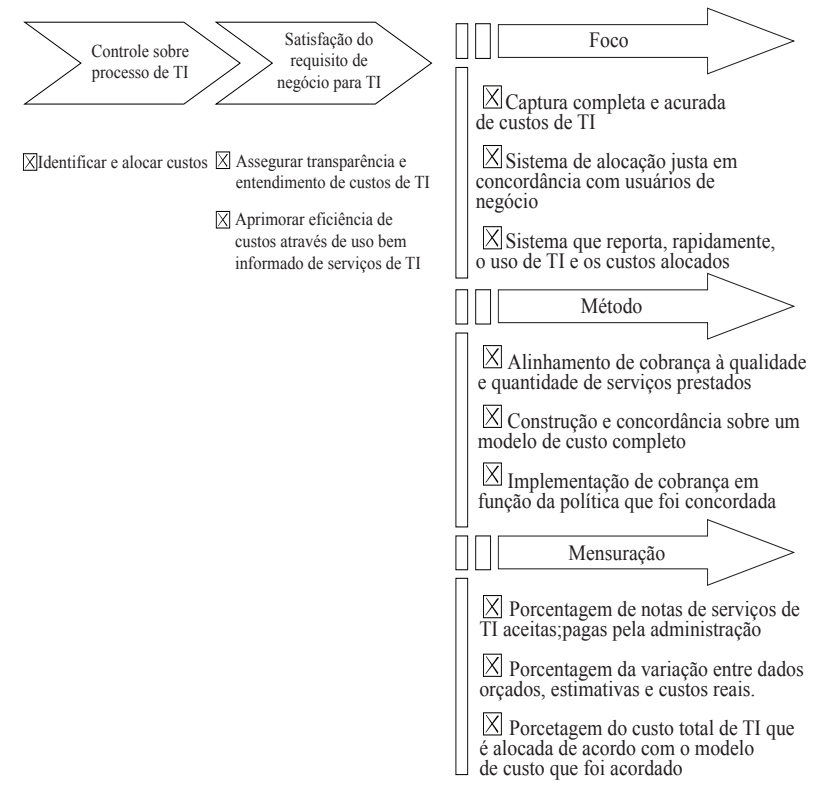

Fonte: Adaptado do CobiT 4.1 (2007). 
Análise simplificada de custos de Tecnologia de Informação

Através da estrutura do CobiT 5 (2012), estabelece-se que um controle sobre os custos de TI deve propiciar transparência e aprimorar o uso intensivo de recursos de tecnologia. O próprio CobiT 5 fornece também algumas diretrizes para o estabelecimento do controle de custos como, por exemplo: (i) acurácia do levantamento de informação sobre custos de TI; (ii) construção de um modelo de custo robusto; (iii) estabelecimento de métricas para avaliação de desempenho das áreas de TI. A versão mais recente do CobiT 5 integra o CobiT 4.1 com outras estruturas do Risk IT (voltado para gestão de riscos de TI) e do Val IT (associado a premissas, custos, riscos e resultados de um portfólio de negócios baseados em IT), definidos pela ISACA (anteriormente conhecido como Information Systems Audit and Control Association). Adicionalmente, o Cobit 5 (2012) enfatiza a distinção entre administração e governança. Dessa forma, considerando a ênfase deste estudo, será utilizada a estrutura apresentada no CobiT 4.1 que possui um maior detalhamento sobre custos de TI.

Segundo o CobiT 4.1, o modelo de custos de TI deve envolver pelo menos 4 elementos, detalhados na Figura 2: (i) definição de serviços de TI; (ii) contabilização dos custos associados a TI; (iii) modelagem e cobrança de custos; (iv) execução de procedimentos de manutenção do modelo de custos.

Figura 2 - Objetivos de controle de custos de TI

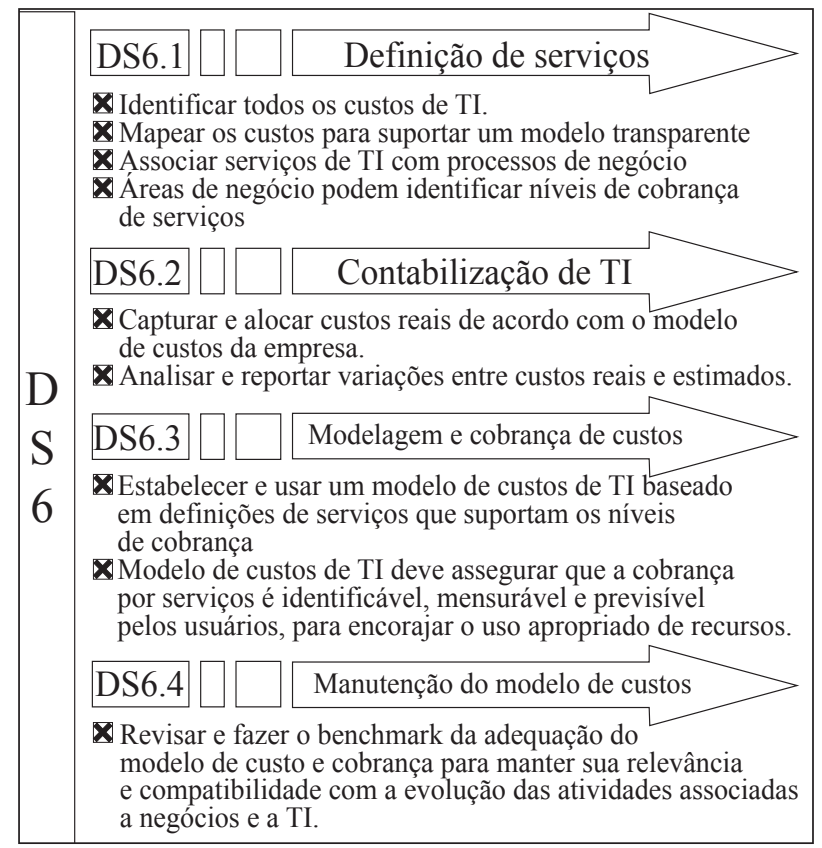

Fonte: Adaptada do CobiT 4.1 (2007).
Considerando a estrutura organizacional e a dinâmica competitiva, Shank (1989) sugere que a gestão de custos de uma empresa não deve estar focada internamente nem depender de direcionadores de custos isolados. Para Neumann et al. (2004), a gestão de custos deve incorporar as seguintes características: (i) ter foco externo; (ii) adicionar valor; (iii) utilizar múltiplos direcionadores de custos; (iv) refletir direcionadores de custos específicos para cada atividade que adiciona valor; (v) fundamentar as atividades de gestão de custos e de conexões entre fornecedores e consumidores; (vi) identificar direcionadores de custos no nível de atividade individual.

Dentro do contexto de direcionadores de custo e métricas de avaliação de desempenho, o CobiT 4.1 apresenta sugestões para orientar o modelo, conforme ilustra a Figura 3.

Figura 3-Métricas e metas

\begin{tabular}{|c|c|c|c|}
\hline & $\mathrm{TI}$ & Processos & Atividades \\
\hline & $\begin{array}{l}\text { - Assegurar transparência e } \\
\text { entendimento de custos de TI } \\
\text { - Aprimorar eficiência de } \\
\text { custo de TI e sua contribuição } \\
\text { para a lucratividade do } \\
\text { negócio } \\
\text { - Assegurar que TI presta } \\
\text { serviços de qualidade com } \\
\text { eficiência de custo, melhorias } \\
\text { continuas e prontidão para } \\
\text { mudanças futuras }\end{array}$ & \begin{tabular}{|l|l} 
& - Desenvolver uma definição \\
$\rightarrow$ & justa e equlibrada de serviços \\
e & e custos de TI \\
s & - Capturar acuradamente os \\
t & - Costos dos serviços de TI \\
a & custos \\
b & - Alocar de maneira justa e \\
e & equilibrada de custos para \\
1 & consumidores de serviços de \\
e & cos \\
c & TI
\end{tabular} & \begin{tabular}{|l|c}
$\rightarrow$ & - Rever custos alocados pela \\
e & administração \\
s & - Alinhar cobranças à \\
t & qualidade do serviço prestado \\
a & - Construir e validar um \\
b & modelo de custos completo \\
e & - Implementar cobrança \\
l & egundo a política acordada \\
e & seguno a \\
c & - Fazer o benchmark de \\
e & custos, regularmente
\end{tabular} \\
\hline & mensura $\uparrow$ & mensura $\uparrow$ & mensura $\uparrow$ \\
\hline & $\begin{array}{l}\text { - Porcentagem de notas de } \\
\text { serviço de TI aceitasspagas pela } \\
\text { administraçãa } \\
\text { - Custo unitário por serviçco } \\
\text { ao longo do tempo } \\
\text { - Porcentagem de satisfaçãa } \\
\text { com modelo de custo de serviços } \\
\text { de TI através de pesquisa com } \\
\text { usuário }\end{array}$ & $\begin{array}{l}\text { - Porcentagem de variância entre } \\
\text { orçamentos, estimativas e custos } \\
\text { reais } \\
\text { - Porcentagem de custo total de } \\
\text { TI que é alocada de acordo com } \\
\text { modelos de custos através de } \\
\text { aceitação } \\
\text { - Porcentagem de custos } \\
\text { questionados por negócios }\end{array}$ & $\begin{array}{l}\text { - Porcentagem de usuários de } \\
\text { negócio envolvidos na definição } \\
\text { de modelos de custos } \\
\text { - Frequência de revisão do } \\
\text { modelo de alocação de custos } \\
\text { - Porcentagem dos custos que } \\
\text { são alocados automaticamente } \\
\text { ou manualmente }\end{array}$ \\
\hline
\end{tabular}

Fonte: CobiT 4.1 (2007).

Considerando a Figura 3, podem ser identificadas algumas medidas de desempenho que permitem avaliar a eficiência dos serviços de TI. Deve-se ressaltar que essas métricas possibilitam alinhar o uso de recursos de tecnologia com os objetivos da empresa. Representam, portanto, mecanismos de controle da performance que, de certa maneira, complementam um modelo de gestão de custos de TI. Mais especificamente, o modelo de custos deve incluir não somente métricas para avaliação 
de desempenho da própria área de TI como também instrumentos para atribuição de custos ou preços de serviços prestados às áreas usuárias.

\subsection{Direcionadores de custo - o modelo ABC}

Cooper (1998) e Cooper e Kaplan (1998) sugerem que as estimativas de custos geradas pelo $\mathrm{ABC}$ são mais confiáveis do que aquelas estabelecidas por métodos tradicionais. Os direcionadores de custo são o primeiro elo no modelo $\mathrm{ABC}$, situados entre os recursos e as atividades. $\mathrm{O}$ direcionador de custo é o processo que faz a junção do custo do recurso com a atividade apropriada. Geralmente, o direcionador mais diretamente identificado está ligado às atribuições diárias, semanais ou mensais dos empregados. Mais particularmente, uma questão importante é avaliar quanto do esforço de um indivíduo está ligado a cada uma de suas atividades. De acordo com a revisão de literatura feita por Neumann et al. (2004), foi verificado que os direcionadores de custo são orientados pelo tempo gasto nessas atividades e suas estimativas são confiáveis. Esses autores também verificaram que, usando o tempo como um direcionador, os custos são desagregados em detalhes suficientes, sem perda de informações relevantes.

$\mathrm{O}$ ABC assume duas visões alternativas das atividades desenvolvidas em uma organização, como está ilustrado na Figura 4 a seguir. Esse modelo foi inicialmente desenvolvido por Turney (1991) e adaptado por Fichman e Kamerer (2002). A primeira das duas visões é denominada de Visão de Atribuição de Custos. Essa visão pode ser acompanhada pelo caminho vertical e mostra o fluxo de custos através de uma determinada atividade. Consiste de recursos, direcionadores de recursos, atividades, direcionadores dos custos de atividades e custo dos objetos - entendido como um bem ou serviço ao qual se pretende atribuir o custo. O segundo á chamado de Visão de Processo e pode ser acompanhado no eixo horizontal. Essa visão mostra o fluxo de desempenho através de informações relacionadas com as atividades, e consiste de direcionadores causais de custos, atividades e medida. O propósito da primeira visão é dar suporte a uma alocação de custos mais precisa e o da segunda é orientar os esforços de redução de custos.

\section{Figura 4 - Estrutura de um modelo ABC}

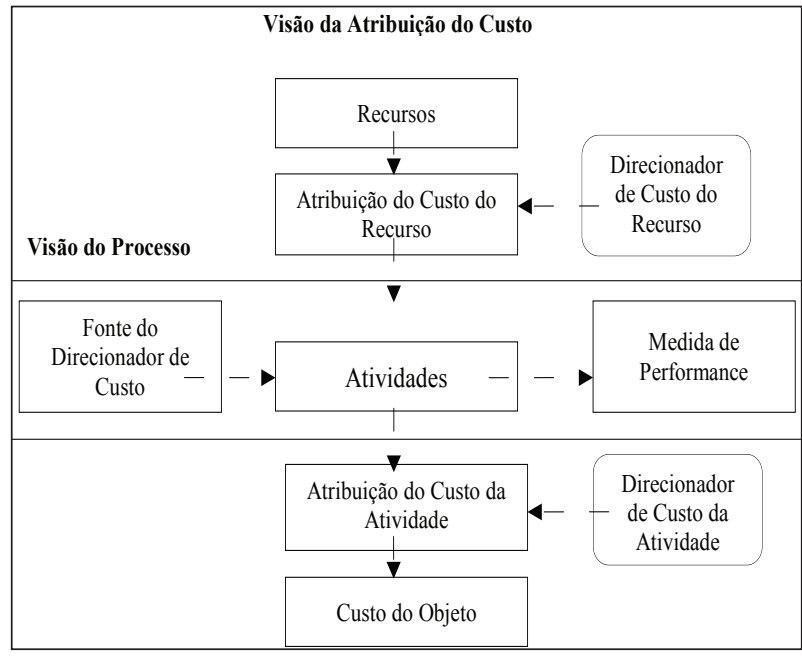

Fonte: Adaptada de Fichman e Kamerer, 2002.

Fagundes (2010) ressalta que a correta alocação de custo de TI é importante para o resultado acurado do método $\mathrm{ABC}$. $\mathrm{O}$ autor esclarece que se pode definir como objeto de custo os produtos, clientes, serviços ou qualquer outra coisa que possa ser contabilizada, acrescentando ainda que as atividades estariam ligadas aos processos associados ao produto da empresa como, por exemplo, receber, entregar, vender, comprar, enquanto os recursos são representados por servidores, sistemas de comunicação, recursos humanos vinculados a alguma atividade.

Fichman e Kamerer (2002) indicam sete passos para a implantação de um modelo ABC: (i) identificar as tarefas repetidas dentro do escopo do esforço $\mathrm{ABC}$, o que é conhecido como o catálogo de serviços (dicionário de atividades); (ii) agrupar as atividades em centros de atividades - coleção de atividades que compartilham o mesmo conjunto de custos gerais; (iii) identificar os recursos usados em trabalhos que se sobrepõem e agregálos em conjuntos por centros de atividades; (iv) identificar as fontes de direcionadores de custos de recursos, isto é, direcionadores que determinam a participação de cada conjunto de custos indiretos atribuível a cada atividade; (v) determinar as bases para calcular os custos unitários de cada atividade; (vi) identificar os custos dos objetos, isto é, produtos, consumidores, serviços, entre outros; (vii) determinar os direcionadores de custos das atividades, ou seja, direcionadores que definem a extensão de consumo de cada atividade por custo de objeto de interesse. 
Análise simplificada de custos de Tecnologia de Informaçấo

Resumindo, a visão de um processo de modelo ABC é desenvolvida de acordo com os seguintes passos: (1) identificar os direcionadores causais de custos, isto é, o que determina o nível ou volume de cada atividade; (2) identificar os medidores de desempenho, ou seja, medidas que podem ser usadas para determinar como de forma eficiente e efetiva cada atividade é desempenhada.

Uma vez definida a estrutura de um modelo $A B C$, o próximo passo é acompanhar seu desempenho por um período de tempo para colecionar dados sobre suas atividades e usar esses dados para determinar padrões de valores para direcionadores de custos de recursos e de atividades, para serem usados na alocação de custos (FICHMAN e KAMERER, 2002).

De uma forma prática, pode-se entender a estrutura de TI ajustada ao modelo $\mathrm{ABC}$, numa forma continuada de atualização de custos. A flexibilidade do mecanismo contábil não interfere e facilita contínuos ajuste e atualização nos processos, característica dos recursos e atividades de $\mathrm{TI}$, aqui considerados como direcionadores de custo. $\mathrm{O}$ uso do método $\mathrm{ABC}$ na análise de decisões de TI também pode gerar benefícios no valor de uma empresa. Por exemplo, estabelecem como hipótese que investimentos em TI de empresas que usam $\mathrm{ABC}$ têm maior probabilidade de obter uma reação favorável do mercado de ações

(ROZTOCKI e WEISTROFFER, 2009).

\section{MODELO DE PRECIFICAÇÃO SERVIÇOS DE TI}

\subsection{Centros de resultados}

Dentro da estrutura organizacional de uma empresa, centros de responsabilidade podem estar genericamente associados a grupos de trabalho, seções, departamentos, filiais, entre outras unidades, uma vez que cada uma dessas unidades da corporação tem algum funcionário que possui responsabilidade pelo desempenho de atividades específicas (ANTHONY e GOVINDARAJAN, 2002). Nesse contexto, quando se considera o departamento de TI como centro de responsabilidade, supõe-se que atividades envolvendo tecnologia podem ser agrupadas e atreladas, pelo menos hierarquicamente, a uma função no organograma.

Justifica-se, portanto, o modelo proposto, pois a própria estruturação de uma empresa em unidades associadas a centros de responsabilidade sugere a adoção de um mecanismo de avaliação baseado em atividades. Assim, o modelo de controle de resultado da área de TI, a ser descrito neste trabalho, leva em consideração o custeio baseado em atividades ou custeio ABC (activity-based costing).

Genericamente, podem ser considerados diferentes tipos de centro de responsabilidade em função de necessidades distintas de avaliação e de levantamentos específicos de valores monetários: (i) centros de despesas; (ii) centros de receitas; (iii) centros de lucros; (iv) centros de investimentos (ANTHONY e GOVINDARAJAN, 2002).

No caso particular da análise de custos do departamento de TI, modelos de controle tradicionais consideram a unidade como centro de despesas no qual são avaliados monetariamente apenas elementos de entrada do centro de responsabilidade. Esses elementos de entrada, no contexto dos centros de responsabilidade, correspondem aos recursos utilizados para a execução de uma determinada atividade que gera saídas na forma de produtos ou serviços, conforme ilustra a Figura 5.

Figura 5 - Comparativo entre Centros de despesa e Centros de resultado

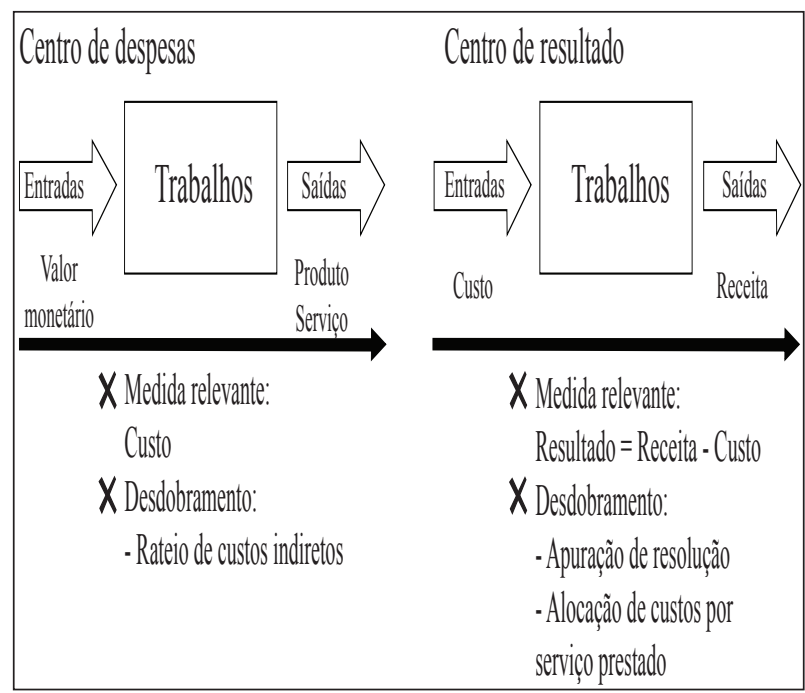

Fonte: Adaptada de Anthony e Govindarajan (2002). 
Em um centro de despesas, o foco de avaliação e controle recai sobre o valor monetário associado às entradas, não havendo uma comparação direta com as saídas produzidas. Dessa maneira, centros de custo não estão associados com receitas e, de certa maneira, seus custos e despesas são indiretos e rateados, segundo algum critério, às unidades produtivas. É importante enfatizar que, na discussão deste trabalho, centros de despesas e centros de custos são equivalentes, embora Anthony e Govindarajan (2002) estabeleçam uma distinção, na qual centro de custos não necessariamente possui responsável facilmente identificável.

Em contraste aos modelos tradicionais de controle, o modelo proposto neste trabalho fundamenta-se na definição do departamento de TI como centro de lucro ou centro de resultado, no qual são avaliados monetariamente não somente os elementos de entrada como também os elementos de saída, de acordo com a Figura 5. Ou seja, na análise de centros de resultado, o departamento de TI realiza um trabalho, isto é, executa atividades que demandam recursos que, por sua vez, possuem um custo. Espera-se que as atividades executadas gerem um produto ou serviço que tenha um valor que possa se refletir na cobrança de um preço pelo uso. Assim, a função de TI passa a ser vista, dentro das organizações, como um negócio independente.

Assim, no modelo em que o departamento de TI constitui um centro de resultado, em contraposição ao custo dos recursos que são utilizados na entrada do processo produtivo, existe um valor monetário ou preço ligado à saída produzida em um centro de resultado, que pode ser repassado aos usuários internos do serviço de TI Dessa maneira, confrontando-se a receita gerencial da prestação do serviço com o custo dos recursos, obtémse uma medida do resultado gerado pelo departamento de TI. O foco da análise envolve, portanto, uma saída na forma de valor monetário do serviço prestado e não necessariamente uma saída na forma simplificada de produto ou serviço.

Deve-se ressaltar que a migração do departamento de TI para um status de centro de resultado pode ser um processo longo que envolve não somente alterações em métodos de orçamento e contabilização como também mudanças culturais. Adaptando, para a área de TI, os argumentos de Anthony e Govindarajan (2002) sobre sistemas de gestão e controle, apesar dos desafios de transformação da cultura organizacional, existem benefícios importantes no modelo de centros de resultado: (i) os clientes encaram TI como aliados e parceiros nas suas operações; (ii) os recursos de TI disponíveis são melhor balanceados em relação às necessidades negociais; (iii) o foco de TI direciona-se para qualidade de serviços e efetividade de custo.

\subsection{Transferência de custos}

$\mathrm{Na}$ estrutura de análise baseada em centros de resultado, portanto, o custo decorrente das atividades de TI pode ser transferido para as áreas usuárias. Desse modo, a análise das atividades do departamento de TI como potenciais geradoras de lucro permite identificar possível valor adicionado pela TI bem como direcionar um uso mais eficiente de recursos. De acordo com Drury (2000), quando um serviço não é cobrado, a natureza humana faz com que seja considerado com displicência, porém, quando o serviço custa dinheiro, existe uma mudança de percepção, tornando-o uma commodity mais valiosa. Nesse contexto, o mecanismo de atribuição de custos em função da utilização de recursos de TI por parte de usuários é comumente definido como chargeback system ou sistema de cobrança, de recuperação de custos ou ainda de preços internos (DRURY, 2000).

O chargeback em TI é um exemplo de preço de transferência, que constitui um conceito familiar em diversas organizações descentralizadas (ROSS, VITALE e BEATH, 1999) e age como dispositivos de coordenação para administrar interdependências entre unidades de negócios individuais (ABDEL-KHALIK e LUSK, 1974).

Conforme Ross, Vitale e Beath (1999), como mecanismo de coordenação, a transferência de preços tem dois objetivos: (i) motivar gestores a tomarem decisões economicamente consistentes que otimizem a alocação de recursos; (ii) apoiar a avaliação de desempenho de unidades de negócio e seus gestores (KAPLAN, 1982). Nessa mesma linha de argumentação, o uso de um sistema 
Análise simplificada de custos de Tecnologia de Informação de chargeback reflete a busca por alguns benefícios específicos no uso de recursos tecnológicos. Por exemplo, conforme Drury (2000), por meio do estabelecimento do sistema de cobrança, empresas podem buscar: (i) uma maior conscientização sobre os custos de TI (COOKE e PARRISH, 1992); (ii) uma maior economia de recursos (FERNBERG, 1993); (iii) um apoio na avaliação de novos projetos de tecnologia (GRAHAM, 1994).

É importante citar que os mecanismos de chargeback não representam conceitos novos, tendo origem nos anos de 1960, quando uma suave recessão promoveu indiretamente o interesse na alocação de custos e na precificação de serviços computacionais para os usuários, em uma tentativa de controlar custos (DRURY, 1998).

Após uma saturação do uso de sistemas de chargeback nos anos 1980 (BUSE, 1988), duas importantes tendências renovaram o foco gerencial nesse mecanismo de cobrança (ROSS, VITALE e BEATH, 1999): (i) algumas organizações, mesmo descentralizadas, expandiram suas estruturas centrais de TI para suportar processos globais e gestão do conhecimento (BROADBENT e WEILL, 1997); (ii) o mercado externo de serviços de TI surgiu e fortaleceu-se como uma alternativa competitiva em relação aos departamentos internos de TI (VENKATRAMAN, 1997).

Em linhas gerais, o sistema de cobrança contabiliza o uso de recursos de computação da empresa e aloca os custos de volta aos usuários (VERNER, TORASKAR e BROWN, 1986). Em termos econômicos, o conceito de cobrança por serviços tem fundamentação na medida em que a alocação de recursos escassos é atingida por meio do estabelecimento de um preço (DRURY, 2000).

Dentro do sistema de chargeback, a cobrança pode ser realizada considerando-se diferentes premissas para definição de preços internos. Assim, o mecanismo de fixação de preços depende dos objetivos de controle da organização. Por exemplo, Sacks (2006) sugere três formas de precificação de serviços, conforme ilustradas na Figura 6: (i) preço equivalente ao custo do serviço prestado; (ii) preço igual ao custo acrescido de um valor adicional referente ao lucro; (iii) preço equivalente ao orçamento total de TI ajustado pela porcentagem de uso de recursos por determinado serviço prestado.

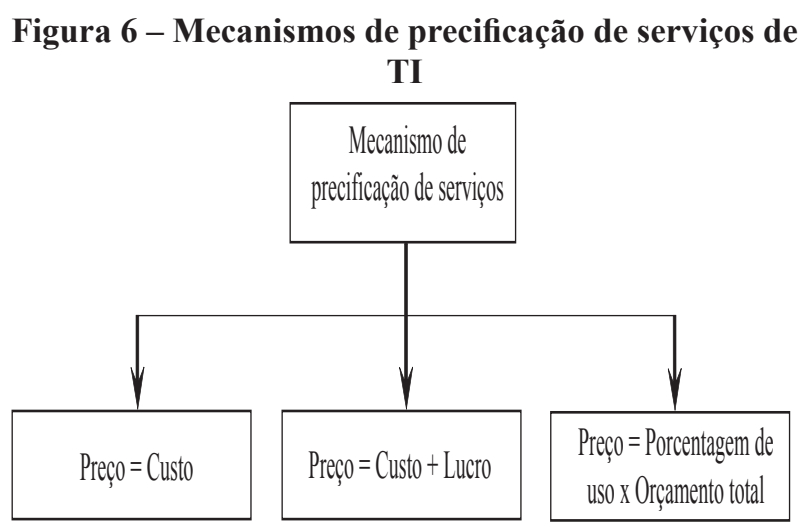

Fonte: Os autores.

Tendo em vista que diversos serviços de TI demandam o uso intensivo de capital intelectual, o custo a ser cobrado de usuários ou consumidores, além de incorporar despesas e investimentos em hardware e software, deve contemplar gastos com mão de obra. Como muitos recursos são compartilhados, ao invés de dedicados (SACKS, 2006), a áreas ou serviços específicos, os custos devem ser rateados em função de grau de utilização por um dado serviço.

Os critérios de apuração e alocação de custos tornam-se, portanto, extremamente relevantes no estabelecimento de uma política de cobrança de serviços de TI, principalmente se forem considerados os dois primeiros mecanismos de precificação e que os principais direcionadores de custo, além do uso de máquina, estão associados aos salários, encargos e benefícios da força de trabalho.

No mecanismo em que preço equivale a custo, Sacks (2006) sugere dois exemplos de modelos para levantamento de custos: (i) o modelo "attorney", no qual o controle envolve um acompanhamento específico de hora por atividade desempenhada; (ii) o modelo mecânico, baseado em um custo ou tempo médio que, inclusive, pode ser divulgado a potenciais demandantes de serviços de TI. Deve-se observar que, dentro desse contexto, o resultado do departamento de TI tende a ser nulo, pois o valor cobrado simplesmente compensa os custos. Assim, o modelo de centro de responsabilidade converge para um modelo de centro de custos, pois o foco da análise direciona-se para a entrada do processo, ou seja, para os recursos e custos. 
Já o mecanismo em que existe lucro embutido no preço, além de possibilitar a incorporação dos custos do serviço, proporciona uma margem de segurança na análise de resultados gerados pelo departamento de TI, principalmente contra eventualidades inesperadas que pressionam os custos ou contra custos de serviços que não são adequados ou plenamente capturados pelo modelo de custos (SACKS, 2006).

Além disso, nesse mecanismo, o departamento de TI pode ser vislumbrado como um centro de resultado, uma vez que pode gerar valor à empresa. De fato, conforme sugerem Mitra e Chaya (1996), apesar dos grandes volumes de investimentos, pesquisadores e gestores têm enfrentado desafios importantes para quantificar benefícios derivados das áreas de TI. Uma das formas de avaliar benefícios ou valor gerado comparando-se preços internos, já embutindo a margem de lucro, com preços de mercado ofertados por fornecedores de serviços externos à empresa, pode-se identificar a competitividade do departamento de TI no uso de recursos.

Considerando uma análise financeira, é importante que os preços sejam ajustados por fluxos de caixa incrementais, uma vez que diversos outros custos podem estar implícitos, conforme destaca Barthelemy (2001). Por exemplo, para comparação entre fornecedores internos e externos, ao preço de um serviço devem ser incorporados os custos de funcionários internos que, teoricamente, acompanham o desenvolvimento de um dado projeto.

Possivelmente, projetos implementados por fornecedores externos exigem uma certa alocação de funcionários internos para acompanhamento, dada a necessidade de facilitação e intermediação com outras áreas na empresa. Prestadores de serviços de TI internos já têm noção da cultura organizacional da empresa bem como da estrutura de sistemas, havendo certa sinergia com as áreas demandantes.

Finalmente, no mecanismo em que o custo é uma porcentagem do orçamento do departamento de TI, o modelo de alocação pode se basear em métricas de utilização que mensuram, basicamente, o consumo de recursos tecnológicos como memória consumida, o tempo de CPU, entre outros fatores. Nesse mecanismo, existe a premissa de que os principais direcionadores de custo podem ser estimados de maneira adequada através do consumo de recursos tecnológicos. Em termos de centros de responsabilidade, há uma orientação maior do departamento de TI para um centro de custos.

No modelo proposto, portanto, busca-se identificar preços de serviços de TI que reflitam não somente os custos dos recursos utilizados como também margens de lucro que compatibilizam uma comparação com fornecedores externos. Nesse mecanismo de precificação, o departamento de TI é definido como centro de resultado, incentivando uma busca por mais eficiência operacional que se reflete em mais competitividade e, possivelmente, em mais lucro gerencial para o departamento e menos despesas efetivas à empresa como um todo.

Além disso, do ponto de vista de cultura organizacional, a cobrança de serviços de TI, conforme já mencionado, previne ou pelo menos desmotiva a demanda indiscriminada por projetos de TI, principalmente quando as diversas áreas na empresa são analisadas sob o modelo de centros de resultado. Afinal, serviços de TI demandados por usuários ou consumidores teriam um custo que poderia impactar a avaliação dos outros centros de resultado.

Apenas para esclarecer definições, usuários e consumidores de serviços de TI, no modelo proposto, são distinguidos conforme estabelece a terminologia do Information Technology Infrastructure Library (ITIL): consumidores são aqueles que pagam ou são proprietários de serviços específicos de TI, e usuários são os indivíduos que utilizam serviços de forma rotineira. Conforme estabelece o ITIL, apesar de a distinção não ser tão relevante do ponto de vista semântico, pode ter impacto relevante no mecanismo de apuração de resultado, uma vez que direcionadores de recursos podem ser diferentes.

Por exemplo, no contexto do ITIL, o ponto de contato primário dos consumidores à área de TI é o administrador ou gerente do serviço prestado, enquanto o ponto de contato primário para usuários tende a ser o help-desk. Demandas de consumidores e de usuários, portanto, direcionam 
Análise simplificada de custos de Tecnologia de Informação diferentes recursos e atividades e consequentemente podem ser avaliadas segundo diferentes custos. Dessa forma, os custos de serviços de TI podem ter como referência os recursos utilizados demandados em função de atividades a serem desempenhadas. Esse mecanismo de avaliação, baseado em atividades desempenhadas e recursos utilizados, distingue-se do modelo tradicional de alocação de custos baseado em rateio. A seguir, discute-se a modelagem de custos através de serviços e atividades.

\subsection{Apuração do custo com base nas atividades}

Uma vez estabelecido o departamento de TI como um centro de resultado, é importante analisar um procedimento para apuração do resultado. No modelo deste trabalho, o preço estabelecido pelos serviços de TI têm dois componentes: o custo e a margem de lucro. Tendo em vista a proliferação de empresas fornecedoras de serviços de TI, o preço do serviço desenvolvido internamente é, de certa forma, balizado por pressões de parceiros ou empresas terceirizadas.

Assim, em uma estrutura na qual o departamento de TI é centro de resultado e em um ambiente no qual o preço do serviço prestado é definido através de competição no mercado, o departamento de TI fica pressionado a manter a competitividade pelo uso mais eficiente de recursos que, ultimamente, deve diminuir os custos por atividade para patamares inferiores aos cobrados por outras empresas de tecnologia que prestariam serviço equivalente. Portanto, o foco da avaliação do departamento de TI deve recair sobre o controle de custos, pois o preço é balizado pelo mercado.

Uma vez que o custo de um serviço de TI decorre principalmente de atividades que demandam recursos da empresa, um modelo de gestão para o departamento de TI deve considerar direcionadores de recursos e de atividades. Nesse sentido, o ABC surge como alternativa metodológica relevante para apuração de custos de serviços. Uma das vantagens da análise baseada em atividades é identificar atividades que não geram valor à empresa (KAPLAN e COOPER, 1998), possibilitando que processos desnecessários sejam minimizados. Devese ressaltar que, no modelo tradicional de avaliação de custos, despesas de overhead são rateadas entre centros de custos e, finalmente, entre os produtos ou serviço, conforme destaca a Figura 7.

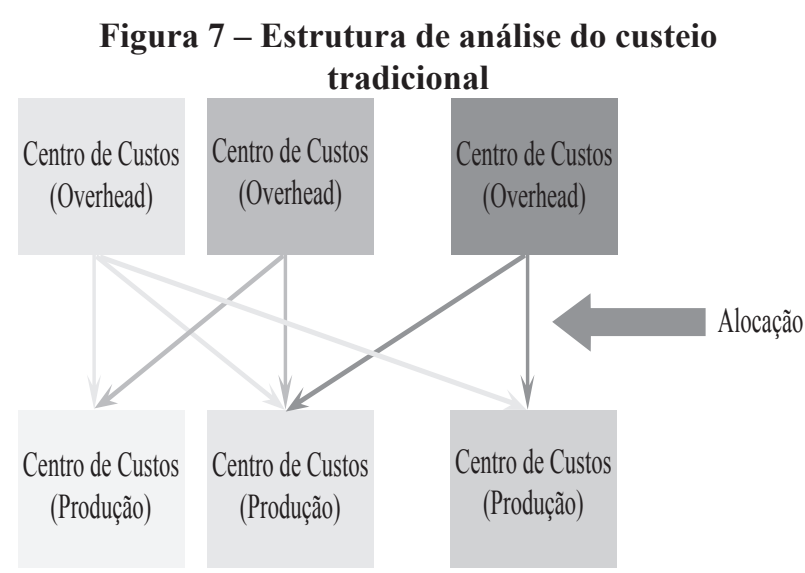

Alocação

\section{Produtos}

Fonte: Kaplan e Cooper (1998).

Note-se que o processo de rateio é, muitas vezes, arbitrário e, mais ainda, mascara ineficiências dos centros de custos, uma vez que todo custo, inclusive custos desnecessários e os associados à ineficiência, é descarregado nos produtos ou serviços. A mudança de visão, quando se passa para um modelo de avaliação baseado em atividades, propicia a análise dos objetos de custeio segundo demanda por atividades e consumo de recursos. Dessa forma, conforme ilustra a Figura 8, ineficiências podem ser detectadas uma vez que o custo de um produto ou serviço reflete diretamente as atividades e recursos, e não um valor que incorpora um rateio de despesas de diversos departamentos que, eventualmente, nem têm relação com a saída final.

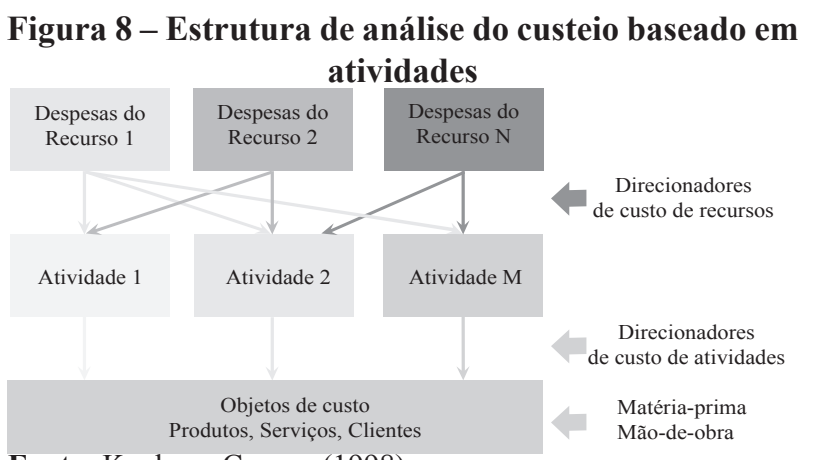

Fonte: Kaplan e Cooper (1998). 
A perspectiva de análise propiciada pelo método ABC segrega direcionadores de custo de recursos e direcionadores de custo de atividades. Os direcionadores de custo de recursos representam os processos que atribuem custos de recursos às atividades correspondentes como, por exemplo, o quanto de um esforço individual é direcionado para cada uma das atividades (NEUMANN et al., 2004). Já os direcionadores de custo de atividades propiciam a atribuição de custos de uma atividade para um objeto de custeio como, por exemplo, o serviço prestado pelo departamento de TI. Um direcionador de custos de atividade é, portanto, uma medida da frequência e da intensidade de uso de uma atividade consumida por um objeto de custeio (TURNEY, 1992).

\section{DESCRIÇÃO DO MODELO}

\subsection{Modelo teórico}

Considerando as diretrizes do CobiT 4.1, um dos objetivos de um controle voltado à identificação e alocação de custos envolve a definição dos serviços de TI. A consolidação de um modelo de custos envolve a elaboração de um catálogo (SACKS, 2006), que descreve os níveis de serviços, incluindo características como tempo de resposta estimado, taxa de disponibilidade e preços de transferência. A confecção do catálogo de serviços implica o desenvolvimento de expertise que culmina no atendimento a uma das metas do CobiT, referente à transparência e ao entendimento dos custos de TI.

É importante destacar que existe um contexto mais amplo, no qual fatores de entrada ou recursos devem ser utilizados em atividades que geram saídas na forma de serviços. A Figura 9, adaptada de estudo do Governo do Canadá (2006) para gestão de TI, ilustra o mecanismo de transformação de recursos e atividades em serviços.

O processo descrito pela Figura 9 aproveita elementos tanto do CobiT quanto do ITIL para estruturação da transformação de recursos e atividades em serviços de TI. Cada um dos serviços como, por exemplo, os voltados para (i) plataforma baixa; (ii) desenvolvimento e manutenção de sistemas; (iii) produção e operações; (iv) telecomunicações, e (v) segurança de TI, demanda atividades que, por sua vez, consomem recursos da empresa. Atividades e recursos podem ser integrados através dos direcionadores de custo do modelo ABC.

Figura 9 - Mecanismo de transformação de recursos em serviços

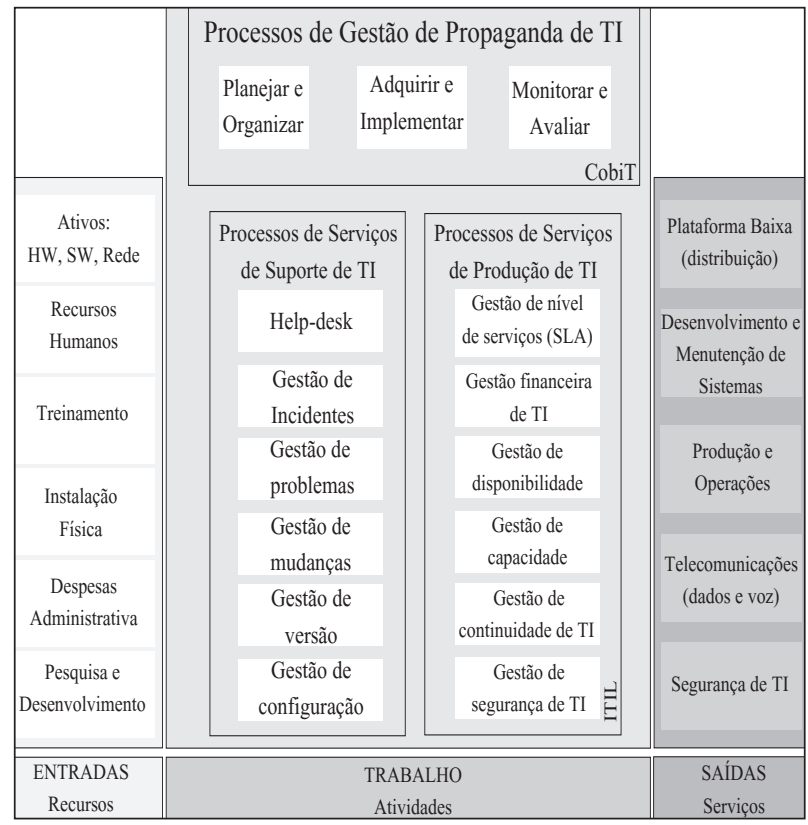

Fonte: Adaptada de Governo do Canadá (2006).

Tendo em vista que recursos são escassos, torna-se imprescindível que TI consiga gerenciá-los de maneira mais eficiente. Reiterando, cada saída na forma de serviço reflete a realização de atividades que utilizam recursos, denotados como entradas do processo. Obviamente, os direcionadores de atividade e de recursos dependem dos tipos de serviços e, mais ainda, do nível de serviço prestado.

Na Figura 10 a seguir, são apresentados de maneira simplificada alguns possíveis serviços prestados por TI e as atividades necessárias para apoiar e entregar esses produtos. Dentro de cada grupo abrangente de saídas, pode-se também discriminar os diferentes serviços para cada agrupamento. A figura ilustra algumas classificações de serviços relevantes, definidos em outros estudos específicos para a análise de custos de TI. 
Análise simplificada de custos de Tecnologia de Informação

Figura 10 - Exemplos de serviços e atividades de TI
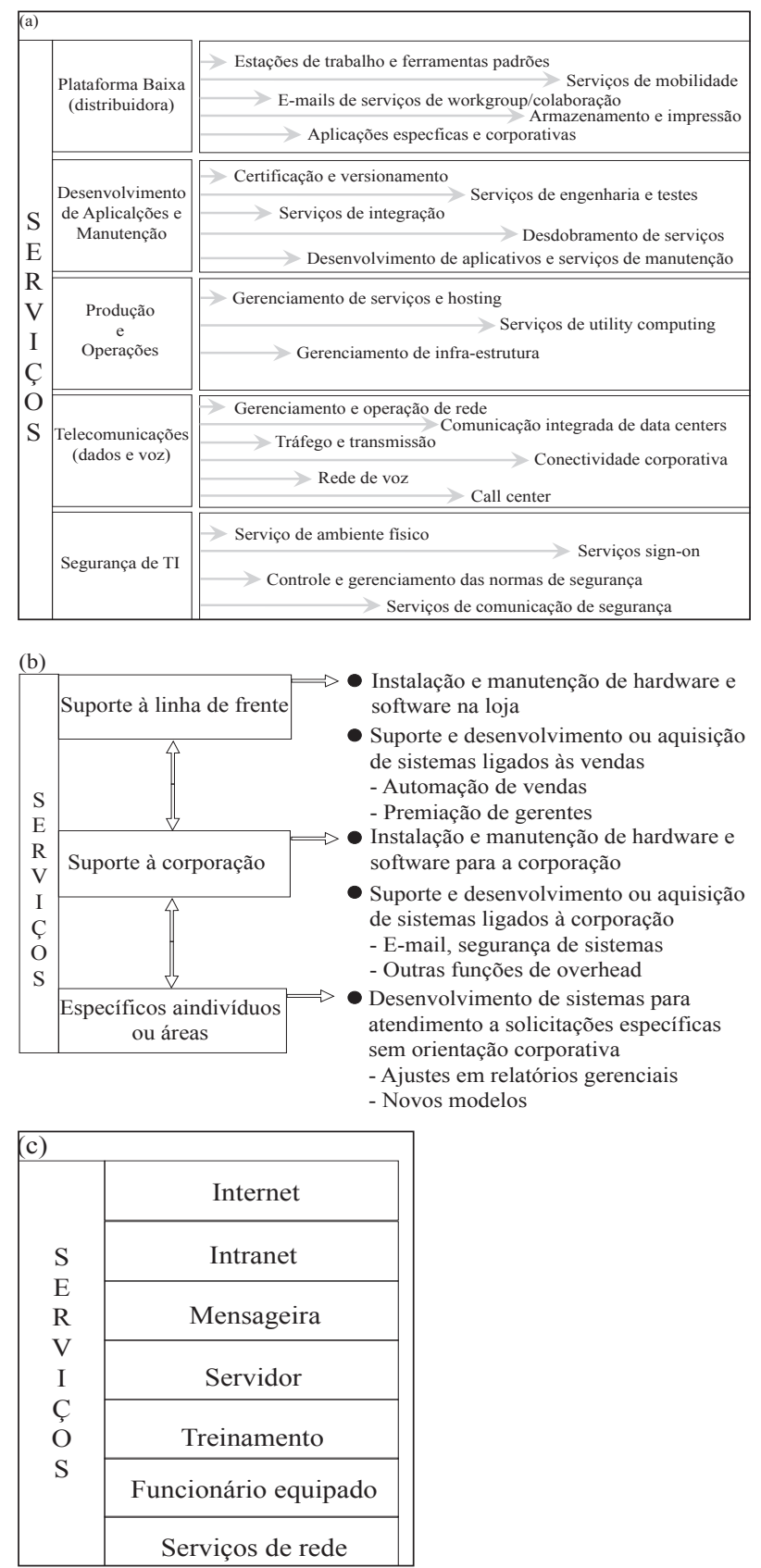

Fonte: Adaptada de (a) Governo do Canadá (2006); (b); (c) Neumann et al (2004).

Uma vez definido o catálogo de serviços prestados pelo departamento de TI, podem ser avaliados os custos pela associação entre cada item de serviço com as atividades necessárias e os recursos utilizados. Esse procedimento de associação representa uma etapa importante do modelo, pois atividades devem ser identificadas e rastreadas, e custos devem ser estabelecidos.

Seguindo o custeio baseado no ABC, torna-se, portanto, imprescindível que os direcionadores de custo de atividades e os direcionadores de custo de recursos sejam levantados. No modelo, direcionadores de custos de atividades representam uma medida quantitativa das saídas de uma atividade, enquanto os direcionadores de custo de recursos servem para mapear despesas com recursos às atividades desempenhadas (KAPLAN e COOPER, 1998). Considerando as características de atividades da área de TI, gastos com mão de obra possuem grande participação no total dos custos e, portanto, uma maneira de associar recursos com atividades e serviços é realizar uma pesquisa com funcionários, na qual eles preenchem estimativas de tempo gasto em cada atividade relativa a um serviço (KAPLAN e COOPER, 1998).

Adicionalmente, algumas atividades de TI podem consumir recursos de máquina e, portanto, a ligação entre atividade e recurso pode ser definida por métricas de utilização de tecnologia como, por exemplo, memória ocupada, transferência de bits, tempo de processamento. Observe-se que a seleção de direcionadores de custo de atividade como, por exemplo, horas de máquina, número de produtos gerados ou horas de mão de obra podem ser detalhadas em subníveis, referentes a tipo de máquina, tipo de produto ou cargo, respectivamente. Afinal, horas de programador, de analista ou de supervisores podem ter custos distintos.

A quantidade de direcionadores de custo de recursos pode ser obtida a partir de pesquisas de atividade nas quais é estimada a alocação de cada recurso à atividade. Assim, por exemplo, o desenvolvimento de um novo sistema envolve diversas atividades que são desempenhadas por recursos humanos e que consomem tempo de máquina. Os recursos humanos, sejam analistas ou programadores, devem definir ou, pelo menos, estimar a porcentagem do tempo ou o número de horas que gastam em cada atividade que executam.

Deve-se observar que, se um programador fosse alocado totalmente para o projeto de desenvolvimento do novo sistema, todo o seu custo seria direcionado para a atividade de programação que, por sua vez, implicaria a alocação total do custo do recurso ao serviço específico. 
Em um caso mais complexo, em que o programador trabalha em vários projetos simultaneamente, não só para desenvolver novos sistemas como também para fazer manutenção de sistemas já existentes, é importante que o programador divida sua carga horária total entre os diferentes projetos dos quais participa, proporcionalmente ao tempo gasto em cada projeto. Dessa forma, o mecanismo de custeio pode ter uma melhor acurácia.

De maneira semelhante, o uso de recursos de tecnologia também pode envolver diferentes atividades, níveis de utilização de máquina, fluxo de dados ou espaço de armazenamento, dependendo do serviço realizado. Servidores e mainframes, por exemplo, podem ter graus de utilização distintos em função da atividade executada e, portanto, torna-se relevante rastrear as atividades para que se possa obter uma melh or estimativa do custo incorrido por serviços.

A definição do grau de detalhamento no modelo de custos reflete uma avaliação, muitas vezes subjetiva, a ser realizada pelo tomador de decisão, sobre a relação de custo-benefício entre acurácia e custo da mensuração (KAPLAN e COOPER, 1998). Por exemplo, a definição de proporção de tempo de um programador entre as diferentes atividades para serviços distintos pode ser arbitrária e ficar a cargo do próprio funcionário. Essa arbitrariedade e delegação de poderes, se, por um lado, diminui a acuidade e possibilita questionamentos com relação à arbitrariedade, por outro lado simplifica o levantamento de dados e delega responsabilidades. No caso de serviços de TI, por exemplo, essas atividades podem estar associadas a procedimentos que exigem programação.

É importante ressaltar que, em geral, as atividades envolvem o uso tanto de recursos tecnológicos quanto humanos e, nesse sentido, o rastreamento de atividades e a contrapartida em custo devem ser bem elaborados. Por exemplo, dentro de um dos serviços de plataforma baixa, a disponibilização de uma máquina para um funcionário envolve não somente o custo do hardware e das licenças de software como também o custo de um profissional do departamento de TI, em função do número de horas gastas para configurar o equipamento.
Considerando relações de custo-benefício para a implantação de um modelo de TI baseado em custeio $\mathrm{ABC}$, deve-se avaliar o ganho adicional em função de um maior detalhamento das atividades. Observe que, dadas a variedade de serviços prestados e as características diferenciadas de cada projeto de TI, as atividades podem atingir um elevado grau de complexidade.

Assim, o modelo de custos deve ser suficientemente detalhado para identificar variações relevantes no uso de recursos, mas também suficientemente simples para propiciar a definição de ferramentas de mensuração e controle que sejam implementáveis e, ao mesmo tempo, de fácil entendimento pela corporação. Um dos desafios para a aceitação de um modelo de custos de transferência de TI é justamente o equilíbrio entre o uso de critérios acurados e a compreensão do mecanismo de precificação.

Para discutir uma situação simples, pode-se supor um modelo de avaliação, no qual os direcionadores de atividade estão associados à hora de mão de obra do pessoal de TI, e os objetos de custeio são os serviços disponibilizados pelo departamento de TI. É importante ressaltar que os objetos de custeio não devem corresponder a componentes técnicos como CPUs ou tamanho de banda (NEUMANN et al., 2004), por exemplo, mas a serviços que são evidentes para os usuários.

Nesse modelo, os serviços relevantes elencados para a análise, seguindo Neumann et al. (2004), foram divididos em sete grupos genéricos, conforme parte da Figura 10: (i) os serviços de Internet; (ii) os serviços da Intranet da empresa; (iii) os serviços de mensageria; (iv) os serviços ligados à utilização do servidor; (v) os serviços de treinamento; (vi) os serviços de equipagem de funcionários; (vii) os serviços de rede. Obviamente, um modelo mais detalhado poderia, para cada um desses grupos, incluir subdivisões, representativas de serviços mais específicos. Afinal, diferentes usuários podem demandar diferentes níveis ou especificações de serviços. 
Análise simplificada de custos de Tecnologia de Informação

Figura 11 - Exemplo do modelo de custos

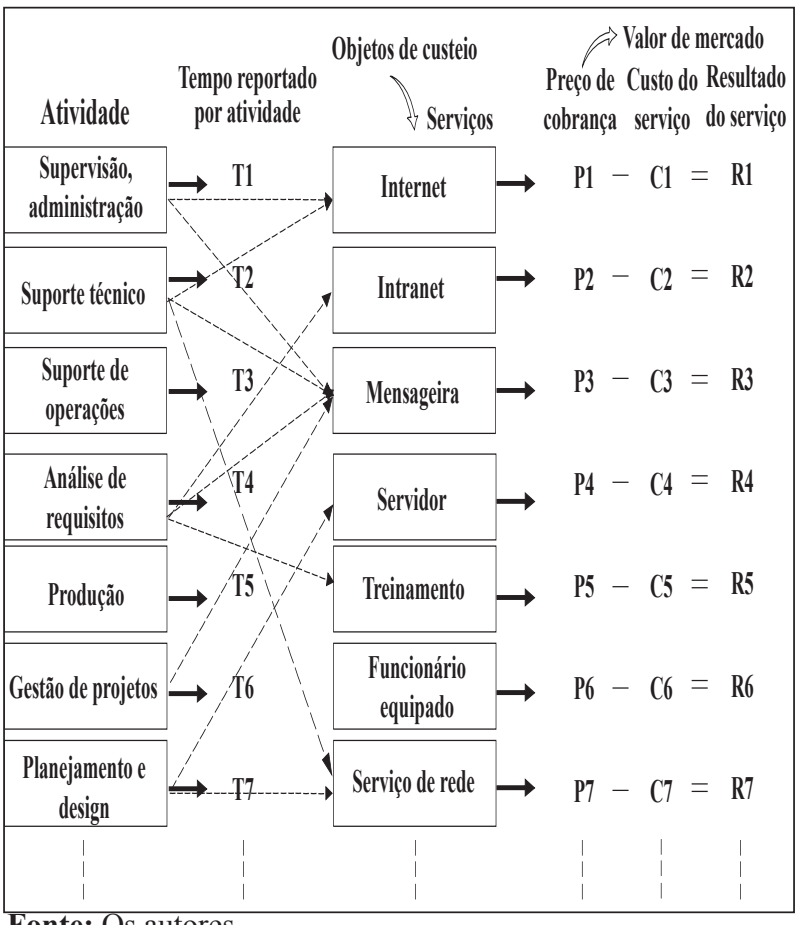

Fonte: Os autores.

Definindo um nível de especificação análogo ao de Neumann et al. (2004), podem ser estabelecidas genericamente as seguintes atividades que poderiam ser o foco para rastreamento e custeio: (i) supervisão e administração; (ii) suporte técnico; (iii) suporte de operações; (iv) análise de requisitos; (v) produção; (vi) gestão de projetos; (vii) planejamento e design. Todas essas atividades demandam esforços da mão de obra e de máquina.

Especificamente para o caso estudado por Neumann et al. (2004), as estimativas de direcionadores de custos relacionados a mão de obra de pessoal alocado no departamento de TI foram considerados relativamente confiáveis e propiciavam informação razoavelmente detalhada da desagregação de custos sem a geração de informação pouco significativa.

Os recursos humanos alocados a cada atividade estabelecem uma planilha de tempo $\mathrm{T}$ gasto por atividade, isto é, de direcionadores de atividades e, dessa forma, é possível definir um intervalo que permite uma estimativa do custo de uma dada atividade e, consequentemente, do custo $\mathrm{C}$ de um serviço específico, bastando somar as horas de cada atividade, multiplicadas pelo seu custo unitário. É claro que diferentes níveis de serviços podem demandar diferentes recursos e, por exemplo, poderiam ser precificados através de uma maior atribuição do tempo reportado.

O custo unitário pode ser estimado pelo valor hora pago a cada recurso humano. Em alguns modelos de custos, o mecanismo de estimação do custo unitário poderia ser mais detalhado, principalmente quando o custo da infraestrutura tecnológica é relevante em comparação com o custo da mão de obra. Ou seja, um determinado serviço poderia ter como direcionadores de atividade não somente o número de horas de mão de obra, mas também o grau de utilização de recursos tecnológicos, implicando o uso de medidas como memória consumida, bytes transferidos, entre outras.

Observe-se que, embora os objetos de custeio, isto é, os serviços, permaneçam os mesmos, os direcionadores de custos incorporam agora recursos como máquina, servidor, mainframe, rede, e os direcionadores de atividade levam em consideração não somente hora de mão de obra como também métricas de uso de equipamentos e outros recursos de TI.

A Figura 11 ilustra o modelo sugerido por Neumann et al. (2004), no qual são definidas as atividades e os objetos de custeio que subsidiam o cálculo do custo $\mathrm{Ci}$ de cada serviço i. O modelo proposto neste trabalho acrescenta um mecanismo de avaliação de desempenho, através do estabelecimento do departamento de TI como centro de resultado.

Seguindo o método de precificação baseado em preço equivalente a preço menos custo (SACKS, 2006), definese um valor de transferência referente ao serviço prestado pelo departamento de TI a outras áreas. Considerando que o mercado de fornecedores externos de TI pode prover serviços de qualidade semelhante, o preço Pi de cada serviço i na Figura 10 pode ser estimado através de uma média de ofertas de potenciais empresas terceirizadas. $\mathrm{O}$ resultado Ri apurado pelo departamento de TI, para cada tipo de serviço $i$, é equivalente à diferença entre o preço Pi ofertado pelo mercado e o custo interno da empresa Ci. Em linhas simplistas, serviços que geram resultado 
positivo devem ser realizados pela empresa, e serviços que geram resultado negativo poderiam ser terceirizados, uma vez que o custo de execução através do uso de recursos internos é maior que o preço de mercado. Porém, é importante destacar que o preço de mercado deve também incorporar não somente o preço cobrado pelo fornecedor externo, mas também o custo de oportunidade de funcionários da própria empresa. Por exemplo, mesmo que o serviço seja terceirizado, eventualmente deve haver um funcionário da empresa para acompanhar ou supervisionar o processo de implantação do sistema. Muitas vezes, características como nomenclaturas ou estruturas organizacionais específicas exigem que a empresa aloque um funcionário para fazer a interface com o prestador de serviço externo. Nesse caso, o custo desse funcionário também deve estar incorporado no preço de mercado Pi estimado para um dado serviço i.

Assim, dependendo do tipo de serviço, o resultado Ri pode ser positivo, evidenciando uma vantagem competitiva com o uso de recursos de TI, internos à empresa. Projetos ou serviços que demandam muito planejamento, controle ou supervisão podem ser candidatos para uso de recursos internos. Mesmo projetos ou serviços com Ri baixo ou negativo podem ainda ser implementados ou prestados com o uso de recursos internos, caso seu papel estratégico tenha um determinado nível de relevância. Aspectos de confidencialidade, segurança, disponibilidade ou performance podem representar argumentos para a não terceirização.

Porém, mais do que definir necessidades e vantagens ou desvantagens de terceirizar serviços, o modelo baseado em centros de resultado propicia a avaliação e o controle de forma mais adequada dos departamentos de TI, dado seu alto grau de investimentos para equipagem e para manutenção. Critérios tradicionais de rateio comumente não permitem uma análise da eficiência do departamento de TI, fazendo com que eventuais possibilidades de ganhos de desempenho não sejam percebidas.

Ao se apurarem resultados associados a TI, não somente ocorre uma motivação para otimização de recursos pela própria área de TI como também ocorre uma inibição de solicitações, por parte de outras áreas da empresa, por serviços que eventualmente não agreguem valor da empresa. Afinal, quando se estabelece um preço, provavelmente há maior discernimento e prudência na demanda por serviços.

\subsection{Estudo de caso}

Este estudo objetiva complementar o modelo teórico que analisa, de forma simplificada, os custos de Tecnologia de Informação (TI) de uma empresa aos quais os autores tiveram acesso. Por motivo de confidencialidade, o nome e os dados relatados são ficcionais, apesar de baseados em uma empresa real.

O presente estudo baseou-se na experiência de uma Instituição de Educação Superior (IES), sendo, portanto, compatível com a realidade empresarial, e espelha de forma adequada os objetivos pretendidos de mostrar a viabilidade do modelo teórico. Deve-se considerar que o enfoque é mais voltado para a estrutura operacional do que para uma realidade numérica de resultados, embora eles sejam compatíveis com os fatos registrados.

Para fins de dimensionamento, pode-se considerar a Empresa Paradigma (EP) como sendo composta por um Conselho Consultivo que representa os interesses maiores da instituição. Esse conselho dá suporte ao Presidente Executivo, o qual, por sua vez, é assessorado por uma Divisão Administrativa e Financeira (DAF). Toda a estrutura organizacional dá suporte à Instituição Universitária Paradigma (IUP), que é dirigida pelo Reitor Acadêmico. Basicamente, trata-se de uma empresa padrão com duas divisões: administrativa e operacional (acadêmica), voltada para a prestação de serviços educacionais do colégio à universidade.

A IUP atua com mais de 2.000 professores e possui cerca de 45.000 alunos nas diversas classes colegiais e universitárias. A IUP continua em fase de expansão. A Divisão de Tecnologia de Informação (DTI), considerando as atividades administrativas e acadêmicas, tem cadastrados cerca de 52 mil usuários. A sede da empresa é localizada em São Paulo, contando com mais quatro unidades operacionais em diversos pontos do país.

a) Aspectos Gerenciais e de Estrutura 
Análise simplificada de custos de Tecnologia de Informação

Os dados apresentados dão uma dimensão da estrutura empresarial suportada pela gerência da DTI, que tem como encargos: responsabilidade pela equipe, processos, sistemas e infraestrutura física de todo um desenvolvimento e aplicação da TI.

Pelo fato de TI ser ferramenta fundamental e ter uma dinâmica de constante superação (a depreciação ocorre em cinco anos) e, portanto, de necessidade de atualização de equipamentos e modelos, a DTI requer permanente atenção. No organograma da EP, a DTI está vinculada diretamente à Diretoria da Presidência, pois os projetos que administra estão relacionados à execução do Planejamento Estratégico e são fundamentais para as atividades de administração, controle e desenvolvimento da instituição.

A DTI utiliza os modelos de gerenciamento CobiT e ITIL. É controlada por auditoria interna e auditoria externa anual. O sistema é gerencial e centralizado, e a execução descentralizada. A equipe de é composta de 67 funcionários na sede e mais 16 atuando nas filiais, totalizando 83 funcionários qualificados na área. No ano de 2010, essa equipe atendeu e concluiu 20.344 solicitações à DTI.

Neste estudo será analisada apenas a estrutura de custos da DTI e seu relacionamento com o sistema de controle da instituição. A Figura 12 apresenta o organograma típico de uma DTI de grande empresa da área de educação, com suas peculiaridades, entre as quais se destacam o atendimento para um grande número de usuários, projetos específicos e a relevância dos Laboratórios de Informática.

Figura 12 - Organograma uma DTI típica de Instituição Universitária

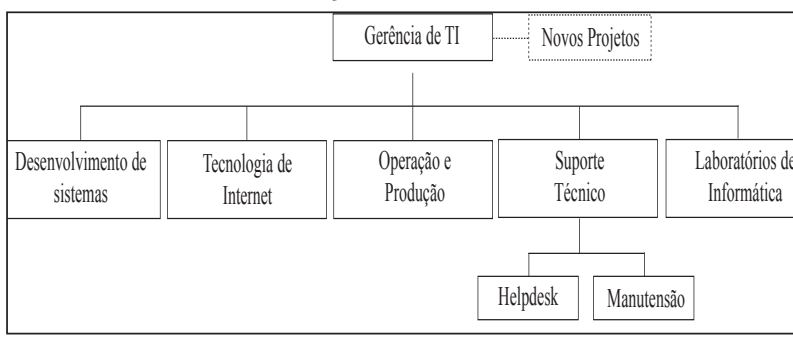

Atualmente, a DTI encontra-se em fase avançada de execução de um projeto de ampliação e modernização dos seus sistemas de gestão, tendo adquirido uma solução Oracle PeopleSoft Enterprise, a qual está em fase de instalação. Dessa forma, os dados apresentados neste estudo não incluem o novo sistema operacional.

Entre os demais projetos em desenvolvimento na DTI, destacam-se ainda a implantação e validação do Data Center principal por modelo de container (CDC), expansão e integração de soluções para gerenciamento de Service Desk (ITIL) e ampliação, implantação e infraestrutura de redes Wireless em unidades externas. Está ainda em desenvolvimento e implantação um grande número de projetos acessórios e principais, próprios da dinâmica da área.

Ainda na área de desenvolvimento de projetos, cabe destaque o Setor de Tecnologia para Ensino a DistânciaEAD, que atua sob a gestão direta da EP, continuando DTI como facilitadora de inovação e suporte tecnológico. A DTI também dá suporte tecnológico para o Ambiente Virtual de Ensino e Aprendizagem Moodle em uso intenso nas diversas instâncias educacionais da instituição e ultimamente também utilizado no Setor de Treinamento e Gestão de Pessoas.

b) Direcionadores de Custo - Exemplo: setor de "Suporte Técnico"

Neste item, objetiva-se apresentar um exemplo integrando o Cobit (Control Objectives for Information and related Technology) e o custeio baseado em atividades (Activity Based Costing) ), o ABC, de acordo com sugestão do modelo teórico. Será usada, como modelo do aplicativo, a seção de Suporte Técnico da DTI. A partir da análise e compreensão desse modelo, pode-se inferir a estrutura das demais seções da DTI.

A Figura 13 mostra a Visão de Processo numa sequência horizontal, desde a origem dos direcionadores de custo até a medida de performance pelos resultados alcançados. A Visão de Atribuição de Custo está exposta no alinhamento vertical a partir da alocação de recursos, atribuição de custos on demand, com repasse total das despesas incorridas, que são distribuídas pelos diversos centros de custo da EP, para fins de controle, definição de preços de serviços, e cálculo do valor final de seu 
principal produto de venda: o valor da mensalidade dos alunos.

Figura 13 - Estrutura de um Modelo de Direcionadores de Custo

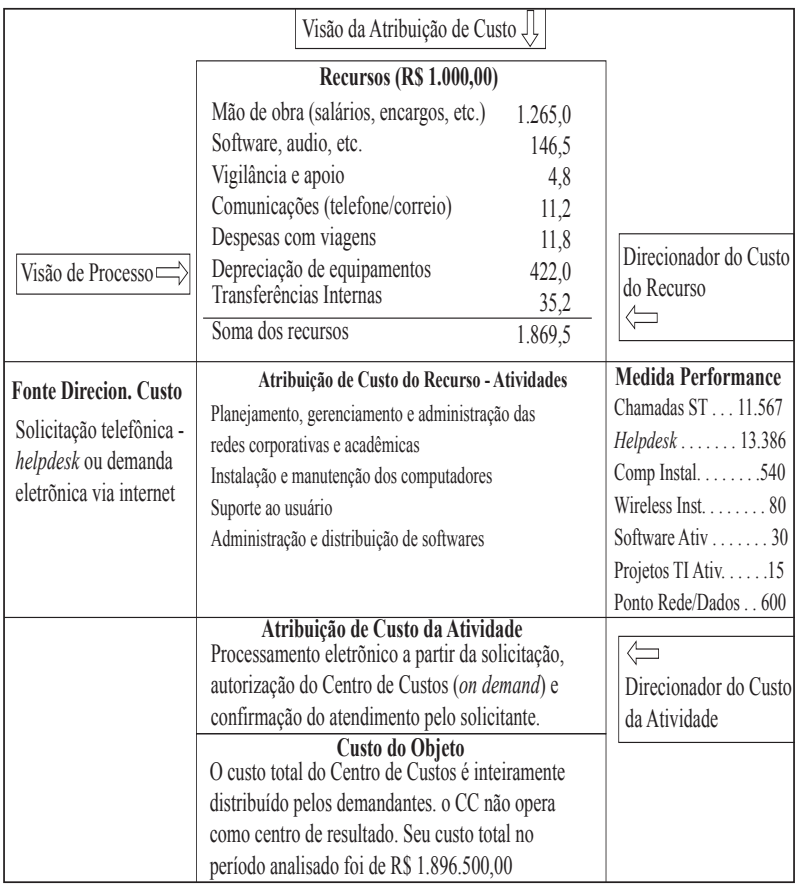

De uma forma prática, pode-se entender a estrutura de TI ajustada ao m MERER, 2002).

c) Modelo de Precificação dos Serviços de TI e Transferência de Custos

O modelo adaptado segue a Figura 5, comparando os valores dispendidos pelo Plano de Contas (anexo ao final deste estudo). Os valores correspondentes às despesas resultam nos valores distribuídos (chargeback) aos demais Centros de Custos da Instituição Acadêmica. O modelo de distribuição de custos (preço = custo) segue o modelo da Figura 6, e acompanha uma das sugestões de Sacks (2006) em que o preço pode ser ajustado ao custo do serviço prestado, cujo sistema em uso é explicado a seguir.

O chargeback em TI constitui um conceito familiar e age como dispositivo de coordenação para administrar a interdependência entre unidades ou centros de custos independentes, tudo resultando num sistema que melhor se adapte aos objetivos operacionais de apropriação direta de custos, resultando numa melhor avaliação da atividade fim da instituição. No caso da Empresa Paradigma, o objetivo é apropriar os custos educacionais resultantes em cada unidade escolar, a serem repassados como mensalidades a serem pagas por seus alunos.

d) Apuração dos Custos na Base das Atividades Uma vez que o custo de serviço de TI decorre principalmente de atividades que demandam recursos da empresa, um modelo de gestão para a DTI deve considerar direcionadores de recursos e de atividades. A Figura 14 mostra uma estrutura esquemática que a seguir é explicada em detalhes.

Figura 14 - Estrutura de Análise de Custeio baseado em atividades do DTI da Empresa Paradigma

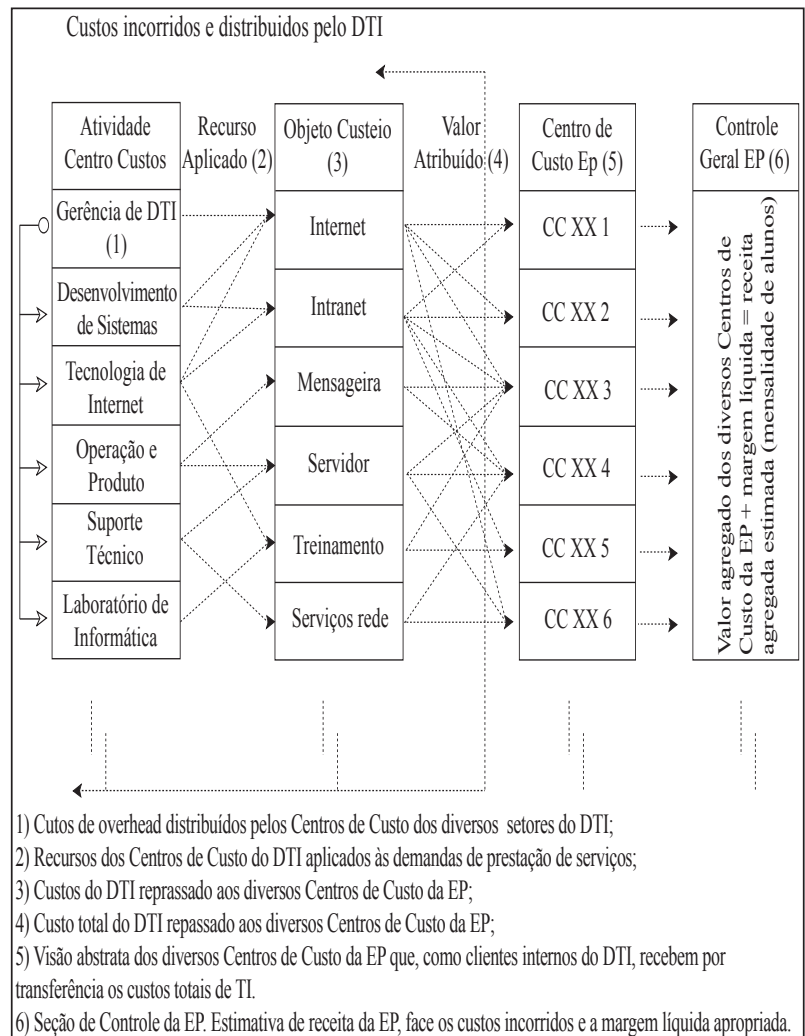

Setor de Desenvolvimento de Sistemas

Esse setor suporta todos os sistemas corporativos ERPs - Gestão Administrativa e Gestão Acadêmica-Financeira, sistemas departamentais próprios e de terceiros, bem como os sistemas via Internet (mais de 100 sistemas). Possui uma equipe especializada que atua nos processos, nos projetos, e na elaboração, implantação e manutenção dos sistemas da organização.

A distribuição das solicitações de serviço aos setores de Desenvolvimento de Sistemas e Tecnologia da Internet, em quantidade por área, é a seguinte: 
Análise simplificada de custos de Tecnologia de Informação

\begin{tabular}{|c|c|c|c|c|c|}
\hline Área & DED & DRF & DAP & IUP & TOTAL \\
\hline Solicitacicos & 794 & 865 & 968 & 2394 & 5021 \\
\hline$\%$ & $15,9 \%$ & $17,3 \%$ & $19,3 \%$ & $47,6 \%$ & $100,0 \%$ \\
\hline
\end{tabular}

A nomenclatura das diretorias é dada a seguir: Diretoria de Ensino e Desenvolvimento (DED), Diretoria de Recursos Financeiros (DRF), Diretoria de Administração e Pessoal (DAP) e Instituição Universitária Paradigma (IUP).

Setor de Tecnologia de Internet

Esse setor preocupa-se com a segurança e infraestrutura de suporte aos sistemas em operação e tem atendido a todas exigências das auditorias externas especializadas. Com relação à infraestrutura, foram padronizados todos os procedimentos da empresa em suas unidades fora de sede.

Setor de Operação \& Produção

Esse setor opera com cinco funcionários, que atendem à demanda de toda a instituição, em regime de 24 horas/dia. Seu escopo inclui controle de estoque de material de TI, geração de relatórios, transferências de arquivo, backup, monitoração do Data Center, impressão, envelopamento e digitalização. Faz interface com os setores administrativos e acadêmicos da instituição e com diversos parceiros externos.

\begin{tabular}{|c|c|c|c|c|c|c|}
\hline $\begin{array}{c}\text { Jobs } \\
\text { Executados }\end{array}$ & $\begin{array}{c}\text { Envelo- } \\
\text { pamentos }\end{array}$ & $\begin{array}{c}\text { Folhas } \\
\text { Impressas }\end{array}$ & $\begin{array}{c}\text { Processos } \\
\text { nos ERPs }\end{array}$ & $\begin{array}{c}\text { Digitalização } \\
\text { Documentos }\end{array}$ & $\begin{array}{c}\text { Impressào } \\
\text { de Cartões }\end{array}$ & $\begin{array}{c}\text { Impressà } \\
\text { de Cracháa }\end{array}$ \\
\hline 18.872 & 187.344 & 1.841 .671 & 678 & 141.720 & 6.450 & 738 \\
\hline
\end{tabular}

Setor de Suporte Técnico

Esse setor é responsável pelo planejamento, gerenciamento e administração das redes corporativas e acadêmicas da instituição, além da instalação e manutenção dos computadores, do suporte ao usuário, da administração e distribuição de softwares. Na execução de suas atividades, atuaram 3 técnicos, 4 analistas e um estagiário. A tabela a seguir exemplifica algumas das atividades do setor.

\begin{tabular}{|c|c|c|c|c|c|c|}
\hline $\begin{array}{c}\text { Chamados } \\
\text { suporte } \\
\text { técnico }\end{array}$ & Helpdesk & $\begin{array}{c}\text { Computadores } \\
\text { adquiridos e } \\
\text { instalados }\end{array}$ & $\begin{array}{c}\text { Antenas } \\
\text { wireless } \\
\text { ativadas }\end{array}$ & $\begin{array}{c}\text { Contratos de } \\
\text { softwares } \\
\text { ativados }\end{array}$ & $\begin{array}{c}\text { Projeto TI } \\
\text { analisados } \\
\text { ativados }\end{array}$ & $\begin{array}{r}\text { Pontos } \\
\text { redes } \\
\text { dadosite }\end{array}$ \\
\hline 11.567 & 13.386 & 540 & 80 & 30 & 15 & 600 \\
\hline
\end{tabular}

Setor de Laboratórios de Informática

Neste ano foi instalado o Sistema Operacional Microsoft Windows 7 como novo padrão nos laboratórios de informática. Os computadores estão padronizados com processadores Intel de 8 núcleos (Core 2 Quad) e AMD com 4 núcleos (Phenon II X 4). Foram adquiridos e substituídos cerca de 300 computadores em diversos laboratórios da unidade principal. Foram instalados 60 iMacs novos e outros micros de última geração para aplicativos gráficos de engenharia, computação, arquitetura e desenho industrial.

\section{Considerações finais sobre o caso}

No modelo de custos da Empresa Paradigma, a DTI atua como uma prestadora de serviços, ordenando e repassando seus custos para os demais centros de custos. Os recursos necessários para manutenção e desenvolvimento da DTI são gerados pela Direção Central da Empresa. A DTI poderá no futuro atuar também como um Centro de Resultados, negociando com terceiros sua expertise em TI. Nesse caso, um overprice em torno de $50 \%$ poderia ser considerado sobre os custos da operação.

Todos os projetos, para o suporte e a instalação de TI, têm sido desenvolvidos e gerenciados in house. Essa política tem resultado na criação de expertise e soluções inovadoras que passam a fazer parte do acervo tecnológico da instituição. Um exemplo aplicado foi o desenvolvimento de um sistema de processamento e distribuição de EAD, com reais possibilidades de ser negociado no mercado de educação e treinamento.

Finalizando, pode-se afirmar que a implantação de um modelo de custos simplificado, como o que foi mostrado e ilustrado na Figura 15, pode ser realizada em instituições de diversos portes, mediante os ajustes necessários ao atendimento das peculiaridades do sistema de controle desejado pelos controladores da empresa. Isso demonstra a praticidade e a flexibilidade do modelo básico sugerido. 
Herbert Kimura, Luiz Carlos Jacob Perera, Maria Thereza Pompa Antunes

Figura 15 - : Resultado da análise da DTI

\begin{tabular}{|c|c|c|c|c|c|c|c|c|c|}
\hline \multicolumn{10}{|c|}{$\begin{array}{l}\text { DIVISÃO DE TECNOLOGLA DA INFORMAÇÃO DA EMPRESA PARADIGMA } \\
\text { MO DISTRIBUIDO POR PLANO DE CONTAS SIMPLIFICADO E UNIDADES SETOR }\end{array}$} \\
\hline & \multirow{2}{*}{\begin{tabular}{|c} 
DISTRIBUID \\
GER. INFO. \\
CC 5
\end{tabular}} & \multirow{2}{*}{\begin{tabular}{|c|} 
TEC. INTER. \\
CC 7 \\
\end{tabular}} & \multirow{2}{*}{$\begin{array}{c}\text { OP. \& PROD. } \\
\text { CC } 8\end{array}$} & \multirow{2}{*}{\begin{tabular}{|c|} 
DESENV. SIST \\
CC 9
\end{tabular}} & \multirow{2}{*}{$\begin{array}{l}\text { SUP. TEC. } \\
\text { CC } 10\end{array}$} & \multirow{2}{*}{$\frac{\text { LAB. INFO. }}{\text { CC } 11}$} & \multirow{2}{*}{ SOMA } & \multirow{2}{*}{$\%$} \\
\hline \multicolumn{2}{|r|}{$\frac{\text { CONTA }}{\text { Descrição }}$} & & & & & & & & \\
\hline T12 & Taxas & 0,00 & 0,00 & 0,00 & $400.000,00$ & 0,00 & 0,00 & $400.000,00$ & $4,33 \%$ \\
\hline 11 & Salários 1 (Salários + Hora Extra) & $258.960,39$ & $213.129,39$ & $253.091,72$ & $1.220 .989,80$ & $837.466,11$ & $536.505,21$ & $3.320 .142,62$ & - \\
\hline 12 & Salários 2 (Férias $\left.+13^{\circ}\right)$ & $57.620,37$ & $43.350,36$ & $56.314,55$ & $271.678,15$ & $177.123,74$ & $119.375,92$ & $725.463,09$ & - \\
\hline 13 & Salários 3 (FGTS) & $25.375,08$ & $19.090,79$ & $24.800,03$ & $119.642,64$ & $78.002,42$ & $52.571,22$ & $319.482,18$ & - \\
\hline 14 & Salários 4 - Benefícios & $30.111,36$ & $29.182,73$ & $58.057,45$ & $144.301,95$ & $172.627,43$ & $145.458,59$ & $579.739,51$ & - \\
\hline- & Total Salários (mão-de-obra) & $372.067,20$ & $304.753,27$ & $392.263,75$ & $1.756 .612,54$ & $1.265 .219,70$ & $853.910,94$ & $4.944 .827,40$ & $53,47 \%$ \\
\hline 21 & Software, audio, etc. & $4.620,00$ & $11.537,76$ & $193.514,98$ & $352.101,30$ & $146.520,00$ & $372.759,00$ & $1.081 .053,04$ & $11,69 \%$ \\
\hline 22 & Conservação, Manut. (Obras+Equip & $2.200,00$ & 880,00 & $166.692,60$ & $6.000,00$ & 0,00 & $135.000,00$ & $310.772,60$ & $3,36 \%$ \\
\hline 23 & Vigilância e Apoio & $7.600,00$ & 0,00 & 0,00 & $11.400,00$ & $4.750,00$ & $143.472,00$ & $167.222,00$ & $1,81 \%$ \\
\hline 24 & Telefone e Correios & $7.392,00$ & $748.800,00$ & $2.704,00$ & $5.760,00$ & $11.520,00$ & $2.496,00$ & $778.672,00$ & $8,42 \%$ \\
\hline 27 & Brindes & $3.769,04$ & 0,00 & 0,00 & 0,00 & 0,00 & 0,00 & $3.769,04$ & $0,04 \%$ \\
\hline 28 & Despesas com Viagens, etc. & $18.820,00$ & $6.537,80$ & $2.822,60$ & $6.367,80$ & $11.520,00$ & $3.365,00$ & $49.433,20$ & $0,53 \%$ \\
\hline 41 & Depreciação & $9.182,28$ & $16.448,40$ & $362.308,20$ & $83.471,88$ & $421.939,32$ & $471.875,52$ & $1.365 .225,60$ & $14,76 \%$ \\
\hline 92 & Transferências Internas & $8.000,00$ & $24.000,00$ & $12.000,00$ & $24.000,00$ & $35.200,00$ & $38.200,00$ & $141.400,00$ & $1,53 \%$ \\
\hline 93 & Apoio, Bolsas & 0,00 & 0,00 & 0,00 & 0,00 & 0,00 & $6.157,00$ & $6.157,00$ & $0,07 \%$ \\
\hline & SOMA & $433.650,52$ & $1.112 .957,23$ & $1.132 .306,13$ & $2.645 .713,52$ & $1.896 .669,02$ & $2.027 .235,46$ & $9.248 .531,88$ & $100,00 \%$ \\
\hline & Percentual (\%) & $4,69 \%$ & $12,03 \%$ & $12,24 \%$ & $28,61 \%$ & $20,51 \%$ & $21,92 \%$ & - & $100,00 \%$ \\
\hline & & & & $(2)$ & & (3) & & & \\
\hline & INVESTIMENTOS ( 1) & $3.200,00$ & $70.000,00$ & $728.000,00$ & $45.800,00$ & $2.475 .000,00$ & $374.600,00$ & $3.696 .600,00$ & - \\
\hline & Percentual (\%) & $0,09 \%$ & $1,89 \%$ & $19,69 \%$ & $1,24 \%$ & $66,95 \%$ & $10,13 \%$ & - & $100,00 \%$ \\
\hline & (1) & $270,77 \%$ & Investimentos & e deprec1a & & & & & \\
\hline & (2) & Servidor e Bac & $\operatorname{cup}(598.000,00)$ & & & & & & \\
\hline & (3) & Substituição de & 300 computado & já depreci & $(1.600 .000$, & & & & \\
\hline
\end{tabular}

\section{COMENTÁRIOS FINAIS}

A crescente relevância de investimentos em áreas de tecnologia de informação nas empresas traz desafios para a análise financeira. Em primeiro lugar, é difícil avaliar os benefícios de projetos de TI, principalmente quando aspectos intangíveis são significativos. Apesar de a intangibilidade ser comum em diversos projetos em uma empresa, no caso da tecnologia, a dinâmica das inovações e a alta variabilidade de possíveis resultados tornam complexo o processo de estimação de benefícios de TI.

Em segundo lugar, uma vez que áreas de TI são tipicamente de apoio, ou seja, não estão ligadas diretamente a atividades de geração de vendas, encontram-se pressionadas com relação ao seu desempenho. Usuários demandam serviços e desempenho sem muitas vezes ter consciência dos custos incorridos para atender certas solicitações.

Nesse contexto, é importante que empresas desenvolvam modelos gerenciais de análise que permitam identificar não somente custos de TI como também seu desempenho. Seguindodiretrizes doCobiT, buscou-sediscutirelementos relevantes para o estabelecimento de mecanismos que permitam levantar gerencialmente o resultado propiciado pelo departamento de TI na prestação de serviços a usuários internos.

O modelo proposto neste trabalho baseia-se na definição do departamento de TI como centro de resultado no qual a receita equivaleria a um valor de mercado, ligado a uma média de preços que empresas de tecnologia externas cobrariam pela prestação de um serviço equivalente, e o custo envolve o levantamento de direcionadores de custos e atividades, seguindo o método de custeio por atividades.

A partir do rastreamento de atividades, é possível identificar processos que fundamentam os serviços e, portanto, obter uma estimativa do custo de um dado serviço ou projeto de TI, evitando uma apuração geral dos custos de TI e posterior rateio entre usuários, comumente utilizada quando se considera um modelo de custos indiretos alocados através de absorção.

Tendo em vista que o rateio tradicional de custos indiretos pode gerar distorções, principalmente quando níveis de serviços de TI diferentes são exigidos por usuários ou 
Análise simplificada de custos de Tecnologia de Informaçáo consumidores distintos, o modelo proposto neste trabalho sugere o uso do custo ABC. Assim, cada cliente, seja usuário ou consumidor, é cobrado gerencialmente em função da utilização de um serviço e, mais especificamente, das atividades desempenhadas e dos recursos consumidos pelo departamento de TI para atender à demanda interna. $\mathrm{O}$ artigo apresenta, além da proposição de um mecanismo de análise de custos de TI, uma aplicação prática trazendo o estudo de uma divisão de tecnologia de informação de uma instituição de ensino superior. Dessa forma, ilustramse alguns detalhes da proposta de avaliação de custos. No entanto, deve ser evidenciado que a complexidade de TI e seu relacionamento cada vez mais intenso com diversas atividades de uma empresa tornam cada vez mais relevante a definição de modelos que permitam alocar de forma adequada os custos da tecnologia.

O objetivo do artigo é apresentar uma proposta de análise agregando estruturas tradicionais em gestão de TI (ITIL e COBIT) com modelo de custeio usado em contabilidade (ABC). Dessa forma, o artigo não foca em comparação de alternativas de análise de TI e também não busca discutir métodos novos. A discussão de um estudo de caso ilustra o uso do modelo, porém não implica em uma justificativa contundente que estabeleça vantagens ou benefícios da proposta. Estudos futuros poderiam comparar diferentes formas de análise de custos de TI, segregando inclusive diferentes tipos de empresa para verificar se a adequação de modelos estaria vinculada às características organizacionais.

\section{REFERÊNCIAS BIBLIOGRÁFICAS}

ABDEL-KHALIK, A. R, LUSK. E. J. Transfer pricing a synthesis. The Accounting Revue, v. 49, n. 1, p. 8-23, 1974.

ANTHONY, Robert N.; GAVINDARAJAN, V. Sistema de controle gerencial. São Paulo: Atlas, 2002.

BANNISTER, F.; MCCABE, P.; REMENYI, D. How much did we really pay for that? The awkward problem of information technology costs. Electronic Journal of Information Systems Evaluation, v. 8, n. 3, p. 159-168, 2001.
BARTHELEMY, J. The hidden costs of IT outsourcing. MIT Management Review, v. 42, n.3, p.60-69, Spring, 2001.

BROADBENT, M.; WEILL, P. Management by maxim: how business and IT managers can create IT infrastructures. Sloan Management Review, v. 38, n. 3, p. 77-92, Spring, 1997.

BUSE, J. Chargeback Systems Come of Age, Datomotjon, 34, p. 47-49. Nov. 1988.

CARR, N. Ten tips for reducing burgeoning IT costs. Director, p. 56-57. August 2007.

COBIT. Control Objectives for Information and related Technology, v 4.1. Information Systems Audit and Control Association, 2007.

COBIT. Control Objectives for Information and related Technology, v. 5. ISAC, 2012.

COOKE, D. P.; PARRISH, E. B. Justifying technology: not measuring up. CIO, v. 5, n. 14, p. 84-85, June, 1992.

COOPER, R. The rise of Activity-Based Costing - Part One: What is an Activity-Based Costing? Journal of Costing Management, v. 2, p. 45-54, 1988.

COOPER, R.; KAPLAN, R. S. Measure cost right: make the right decisions. Harvard Business Review, v. 65, n. 5, p. 96-103, 1988.

CORRÊA, R. C. Custos em empresas prestadoras de serviços de informática: aplicação do ABC. Dissertação de mestrado em engenharia de produção. Universidade Federal de Santa Catarina, 92 p., 2002.

CRONHOLM, S.; GOLDKUHL, G. Strategies for information systems evaluation: six generic types. Electronical Journal of Information Systems Evaluation, v. 6, n. 2, p. 65-74, 2003. 
CROWLEY, A. The new metrics. PC Week, p. 21-24, September, 1994.

DRURY, D. H. Assessment of chargeback systems in IT management. INFOR, v. 38, n. 3, p. 293-313, 2000.

DRURY, D. H. Temporal analysis of information technology chargeback systems. Information Resources Management Journal, v. 11, n. 2, p. 5-12, Spring, 1998.

FAGUNDES, E. M. Um modelo de custeio ABC para TI. Disponível em: <http://www.efagundes.com /artigos/ Modelo_de_Custeio_ABC_para_TI.htm>. Acesso em: 22 nov. 2010.

FERNBERG, P. M. How safe is your mail center? Are you sure? Managing Office Technology, v. 38, n. 9, p. 29-30, September, 1993.

FICHMAN, R. G.; KAMERER, C. F. Activity Based Costing for component-based software development. Information Technology and Manegement. v. 3, p. 137-160, Kluver, 2002.

GOVERNO DO CANADÁ. Profile of information technology (IT) services, version 1.0, final draft. Chief Information Officer Branch, Enterprise Architecture and Standards Division, 2006.

GRAHAM, S. Client server sites can reap benefits, policies, and strategies of performance evaluation methods. Computing Canada: 8, March, 1994.

ITGI. Information Technology Governance Institute. Governance global status report, 2004. Disponível em: <www.itgi.org>. Acesso em: 15 out. 2007.

KAPLAN, R. S. Advanced management accounting. New Jersey: Prentice Hall, 1982.

LACITY, M. C.; KHAN, S. A.; WILLCOCKS, L. P. A review of the IT outsourcing literature: insights for practice. Journal of Strategic Information Systems, v.
18, p. 130-146. 2009.

LUFTMAN, J.; ZADETH, H. S. Key information technology and management issues 2010-2011: an international study. Journal of Information Technology, v. 26, p. 193-204, 2011

LUFTMAN, J.; BEN-ZVI, T. Key issues for it executives 2010: judicious progression towards post recession times. MISQ Executive, v. 9, p. 49-59, 2010.

MITRA, S.; CHAYA, A. K. Analyzing cost-effectiveness of organizations: the impact of information technology spending. Journal of Management Information Systems, v. 13, n. 2, p. 29-57, 1996.

NEUMANN, B. R.; GERLACH, J. H.; MOLDAUER, E.; FINCH, M.; OLSON, C. Cost management using ABC for IT activities and services. Management Accounting Quarterly, v. 6, n. 1, p. 29-40, Fall, 2004.

OH, W.; PINSONNEAULT, A. On the assessment of strategic value of information technologies: conceptual and analytical approaches. MIS Quarterly, v. 31. n. 2, p. 239-265, June 2007.

O'LEARY, M. Birth of a Salesman, CIO, 5(13), June 1, 1992. p. 30-35.

OPFER, N. D. Total cost ownership for information technology. AACE International Transactions: IT71, 2001.

RYAN, S.; HARRISON, D. A. Considering social subsystem costs and benefits in Information Technology investment decisions: a view from the field of anticipated payoffs. Journal of Management and Information Systems, v. 16, n. 4, p. 11-40, 2000.

ROSS, J. W.; VITALE, M. R.; BEATH, C. M. The untapped potential of IT chargeback. MIS Quarterly, v. 23. n. 2, p. 215-237, June 1999. 
Análise simplificada de custos de Tecnologia de Informaçáo

SACKS, S. 10 Steps to modifying user behavior to reduce IT costs. White paper, CA Executive Technology Advisors, February, 2006. Disponível em: <https:// ca.com/files/WhitePapers/29575_10steps_supplement. $p d f>$. Acesso em: 05 jul. 2009.

SHANK, J. Strategic costs management: new wine, or just new bottles? Journal of Management Accounting Research, p. 47-65, Fall, 1989.

TURNEY, P. B. Common cents. Cost Technology, 1991.

KAPLAN, R. S. e COOPER, R. Cost and Effect: Using Integrated Cost Systems to Drive Profitability and Performance. Harvard Business School Press, 1998.

TURNEY, P. B. Common cents: the ABC performance breakthrough. Cost Technology, 1992.

VENKATRAMAN, N. Beyond outsourcing: managing IT resource as a value center. Sloan Management Review, v. 38, n. 3, p. 51-64, 1997.

VERNER, J. M.; TORASKAR, K.; BROWN, R. information systems chargeout: a review of approaches and future challenges. Journal of Information Technology, v. 1, n. 1/2, p. 101-117, 1986. 